\title{
Key features and novel trends for developing cost engineering methods for forged components: a systematic literature review
}

\author{
Claudio Favi ${ }^{1}$ (D) $\cdot$ Federico Campi ${ }^{2} \cdot$ Marco Mandolini $^{2} \cdot$ Irene Martinelli ${ }^{3} \cdot$ Michele Germani $^{2}$
}

Received: 14 September 2020 / Accepted: 1 July 2021 / Published online: 26 August 2021

(C) The Author(s) 2021

\begin{abstract}
Engineering design shows a growing interest in exploring cost analysis to anticipate manufacturing issues and integrate production aspects within the product development process. This research aims to highlight key elements (inputs, parameters, models) to accurately predict the cost of a forged part using a complete model, with important information that can be available during the design phase. For this purpose, a systematic literature review of existing engineering methodologies developed for cost analysis of forged parts (i.e., cost estimation, $\mathrm{DtC}$, and $\mathrm{ABC}$ ) was performed with characterizations of the different approaches for evaluating the most important topics related to this objective. As a result, the most important insights related to the aim of this review are provided: (i) among quantitative methods, analytical and parametric models are the most suitable approaches to develop a cost estimation, (ii) a cost model based on a linear equation supported by single or multiple variables seems to be the most accurate tool to establish a robust cost analysis in the design of forged components, and (iii) input parameters related to the material type and geometrical features are the most critical cost-drivers in the cost assessment. Moreover, this review contributes to identifying emerging applications and obsolete topics, providing the ground to investigate unexplored areas relevant to future research.
\end{abstract}

Keywords Systematic literature review $\cdot$ Engineering knowledge $\cdot$ Forging $\cdot$ Cost model $\cdot$ Cost assessment $\cdot$ Material processing $\cdot$ $\mathrm{CAD} \cdot \mathrm{CAE}$

\section{Introduction}

Design and production are engineering activities that belong to two different entities firmly integrated into modern enterprises.

Claudio Favi

claudio.favi@unipr.it

Federico Campi

f.campi@univpm.it

Marco Mandolini

m.mandolini@univpm.it

Irene Martinelli

Irene.Martinelli@bhge.com

Michele Germani

m.germani@univpm.it

1 Università degli Studi di Parma, Parco Area delle Scienze 181/A, 43121 Parma, Italy

2 Università Politecnica delle Marche, via Brecce Bianche 12, 60121 Ancona, Italy

3 Baker Hughes, Via Felice Matteucci 2, 50127 Firenze, Italy
Today, globally operating companies are required to run in an uncertain environment facing the design of complex products with several constraints such as minimal weight, minimum cost, high quality, manufacturability, reliability, and short time-tomarket. System engineering methods and tools are necessary to tackle these issues and close the gap between the design and the manufacturing departments. Literature shows how manufacturing issues were coupled within the design process creating integral approaches known as "concurrent engineering" [1] "integrated product development" [2], and "quality function deployment" [3]. First attempts to consider upstreaming feedbacks from the manufacturing into the engineering and design activities were made in the early ' 80 by the birth of Design for Manufacturing and Assembly (DfMA) [4]. Over the years, other objectives (maintenance, quality, reliability, disassembly) were integrated beyond manufacture and assembly (DfX techniques), mainly focused on cost reduction. Thus, design methodologies, based on cost analysis, were developed such as design-to-cost (DtC) [5], activity-based cost (ABC) [6], and cost estimation [7]. These methodologies couple economic constraint, with other paradigms such as manufacturability, assembly, and sustainability. 
Even though the forging process is one of the oldest methods of metalworking, it is one of the most challenging industries for the development of mechanical components. Forging remains a cost-effective manufacturing technology to this day due to the possibility to achieve desirable mechanical properties for the component-including a very high degree of tensile strength - at an attractive price-point. At its core, this process consists of forming raw metal without allowing the material to melt completely. The metal remains in a solid-state while the piece goes through a combination of forming techniques such as hammering, rolling, or pressing. While there are many forging variations, each with its distinct advantages, most involve heating the work-piece to very high temperatures to facilitate these shaping processes. The benefits offered by forging, compared with other production processes, can be summarized as superior quality combined with lower manufacturing costs. The standard of quality is due to the favourable mechanical properties of forged parts, such as high strength and toughness, an uninterrupted fiber flow, close tolerances and a good surface quality. The cost benefits achieved using forging techniques can be considerable, but do depend on the specific part considered and on the previously used production method. Individual cost factors include:

i. Low material input: almost the complete initial volume of the billet is processed into the finished part (savings can be as great as $75 \%$ compared to machining).

ii. Use of low-cost raw materials: lower-cost steel grades with lower initial strength characteristics can be used to achieve the same mechanical properties obtainable in machined parts.

iii. Reduction/elimination of subsequent machining processes: metal removal after forging is necessary only in the case of geometries that present particular features (i.e., recesses, undercuts, or threads).

iv. High productivity: stroking rates vary based on the dimensions of the workpiece (i.e., up to 200 pieces/min for small workpieces produced from wire on horizontal forging machines).

v. Facility for integration of several functions/geometries in a single component: cold extruded parts often provide an opportunity for re-engineering to create lower-cost designs.

The application of knowledge-based systems provides efficient solutions to complex engineering design problems such as forging. It is particularly true for cost estimation, where multiple engineering aspects need to be faced. Implicit (tacit) knowledge lies in a breadth of professional expertise beyond that of a single forging product designer. The engineering design activities, such as the cost analysis of forged parts, suffer from this issue. The way to reinject manufacturing knowledge in the early design phase and how to use it to calculate manufacturing costs are still open points.
1.1 Research questions in the cost analysis of forged parts

Based on the defined issues, three research questions emerged from the analysis of the literature in this field:

1. What are the most reliable cost analysis methods in the engineering design of forged components?

2. To what extent, the forging manufacturing knowledge has been used to derive numerical models and inputs for cost analysis methods?

3. To what extent, virtual design tools have been investigated as potential inputs for cost analysis methods?

\subsection{Objective of the research}

This research aims to highlight the main aspects (inputs, parameters, models) to accurately predict the cost of a forged part using a complete model, with important information that can be available during the design phase. For this purpose, an in-depth review of existing engineering methodologies developed for cost analysis of forged parts (i.e., cost estimation, $\mathrm{DtC}$, and $\mathrm{ABC}$ ) was performed. This research leads to the characterization and classification of the different approaches encountered in the literature, evaluating the most important topics related to this objective.

\subsection{Positioning of the research}

The present work focuses on the design of components that need to be manufactured with forging technologies. The high competition in the forging market is why, besides the quality, the forged part's price is the critical parameter that often determines the vendor's selection. Despite the forging technology is consolidated and relatively well known, this process is the most difficult to implement. Producing a proper forging of a complicated shape, which will meet the requirements of the recipient regarding the precision and quality (i.e., automotive, military, and aircraft industries), requires high experience and knowledge from designers, engineers, and technologists. In the forging industry, cost estimation is a crucial activity due to the several aspects that include the raw material consumption, the use of dedicated machines and their shop floor occupation, the design of customized dies and tools, the sequence of operations, etc. Indeed, the forging industry moved from a traditional and consolidated technology towards a complex and automatized environment, which includes newly processes (e.g., precision forging) [8], automation and robotics (i.e., manipulation and inspection) [9], and the feasibility to produce forged parts with complex shape/geometry that were considered impossible to fabricate by engineers in the 1970's and 1980's [10]. 


\subsection{Relevance of the research}

This research's relevance lies in the possibility to identify the most reliable cost analysis methods in the engineering design of forged components. Cost analysis is part of the product development process. It requires many disciplines from design to manufacturing, passing through metallurgy, mechanics, etc. Cost analysis translates tacit (implicit) knowledge, which lies in the high experience and knowledge of designers, engineers, and technologists, to explicit knowledge, that can be reinjected in the development of manufacturing-compliant products for Design-to-Cost activity. The analysis is focused on those key factors (i.e. models, inputs, materials, technologies, geometrical and process parameters) that characterize the cost assessment methods and the quality of the outcomes. The literature analysis results were then used to make suggestions for future studies and drive researchers and practitioners to develop compliant tools for the robust assessment of costs in the early design stages. In scientific and academic literature there are no review papers focused on the estimation of forging costs, but only reviews focused on forging equipment, in particular on methods of increasing the life of forging tools $[11,12]$ or on degradation mechanisms [13]. Other authors focused their research on force reduction methods [14], measurement techniques [15], material behaviour [16, 17], or developments in a particular forged product [18]. The current review provides comprehensive coverage by reviewing 85 documents from 1970 until now. It provides a detailed analysis of different aspects of the literature to identify research trends through a structured review process.

\subsection{Contribution of the research}

This review encompasses several topics related to the engineering knowledge in the field of forging. The contribution of this research work deals with the possibility to identify important aspects related to the cost analysis of forged parts such as the definition of cost functions and key input parameters, the differences in forging technologies and materials to be modelled, as well as the introduction of a virtual design tool for a more accurate cost analysis (i.e., $\mathrm{CAD}$ and $\mathrm{CAE}$ tools).

The paper is structured as follows: after this introduction, the second section presents the methodology applied to collect relevant literature for the review and assumptions. The third section introduces the classification framework with a dedicated discussion about the clustering approach for the retrieved methodologies. The fourth section presents the classification of literature and the main results following the defined framework. Lastly, conclusions are outlined, and viable future research directions are proposed.

\section{Materials and methods}

A systematic literature review (SLR) was used to investigate engineering design methodologies for cost estimation and
Fig. 1 The framework of the systematic review

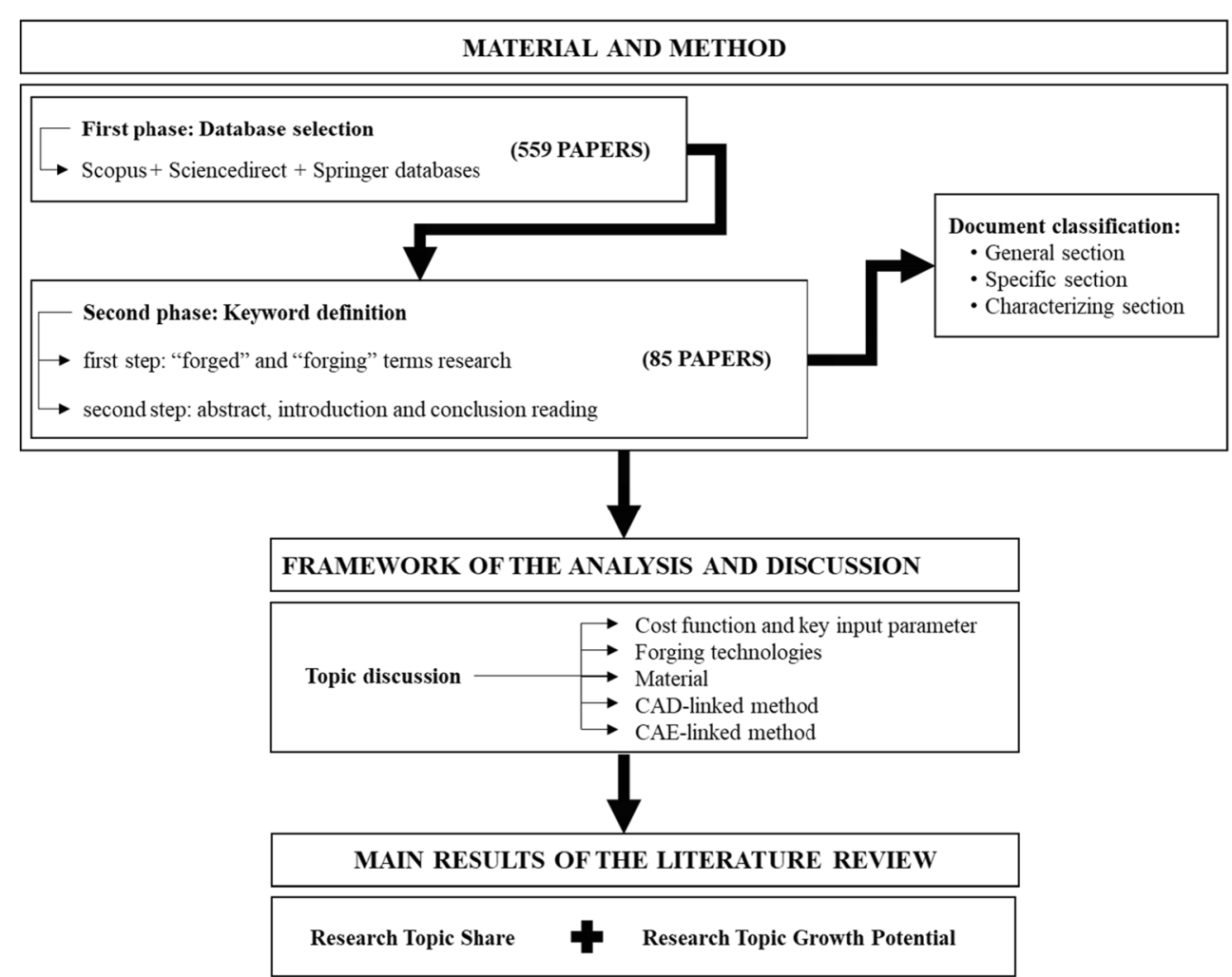


analysis of forged products. SLR has been conceived to be robust, repeatable, objective, precise, and scientific. Section 2 is structured as follows: (i) the selection of databases used for the review (Section 2.1), (ii) the definition of keywords used to obtain topic-related documents (Section 2.2), (iii) the method used for the analysis and classification of documents (Section 2.3), and (iv) the bibliometric analysis (Section 2.4). Figure 1 represents the overall framework of the review.

\subsection{Database selection}

The literature review started in the first quarter of 2020 (January-April) analysing documents published until the end of 2019. The investigation is carried out through three databases: (i) ScienceDirect, (ii) Scopus, and (iii) Springer with no constraints placed on journals or disciplines. The research included conference/journal papers, and technical reviews, excluding books, book chapters', thesis, and technical reports. The language used for the study was limited to English. All fields, including article title, abstract, keywords, and main text, were used for the research in the three databases. The study was conducted without applying any filters related to the publication years. This choice reflects the fact that forging is one of the oldest technologies with continuous advancements over time. Pioneering works about engineering cost analysis were developed, in the first place, for this technology. The retrieved works cover a timeframe longer than 40 years. An overview of the time distribution of research works is presented in Fig. 2, starting from 1977.

\subsection{Keywords definition}

The search was structured in two phases using the following keywords. In the first phase, the term "forging" was combined using the "AND" operator with all following keywords: "design to cost," "cost estimation," "production part costing," "should cost," and "activity-based costing." A total number of 559 documents were found in this first phase. For the ScienceDirect database, the research was limited to title, abstract, and author-specified keywords fields available in the advanced search, due to the massive number of articles retrieved by the first analysis (higher than 10000).

To reduce this large number of papers, considering only the relevant ones for the SLR, a refinement (second phase) was conducted based on the following criteria:

- for each document, the terms "forged" and "forging" were searched within the document. If these terms appeared only in the references or as "examples" within the text, those documents were discarded;

- for all the other documents that passed this first screening, abstract, introduction, and conclusion were read to evaluate if the document is compliant or not with the SLR topic.

Adopting the mentioned criteria, the overall number of articles passed from 559 to 85 . Documents are grouped as follows: (i) 65 journal papers, (ii) 18 conference proceedings, (iii) 2 conference keynotes. Table 1 summarizes the number of documents collected in this phase and the screening process based on the selected keywords.

\subsection{Document organization}

After the screening presented in the previous section, all the references were collected, organized, and analyzed. A dedicated spreadsheet was developed with this aim, clustering the relevant information (Table 2), and using the following categories and summarized:

- General section: this section included the primary author, other authors, title, year of publication, type of paper, journal or conference name, and DOI.

- Specific section: this section included the main topic of the paper, related topics, paper objective, paper novelty, result and, limitations.

Documents per year

Fig. 2 Documents distribution over the years

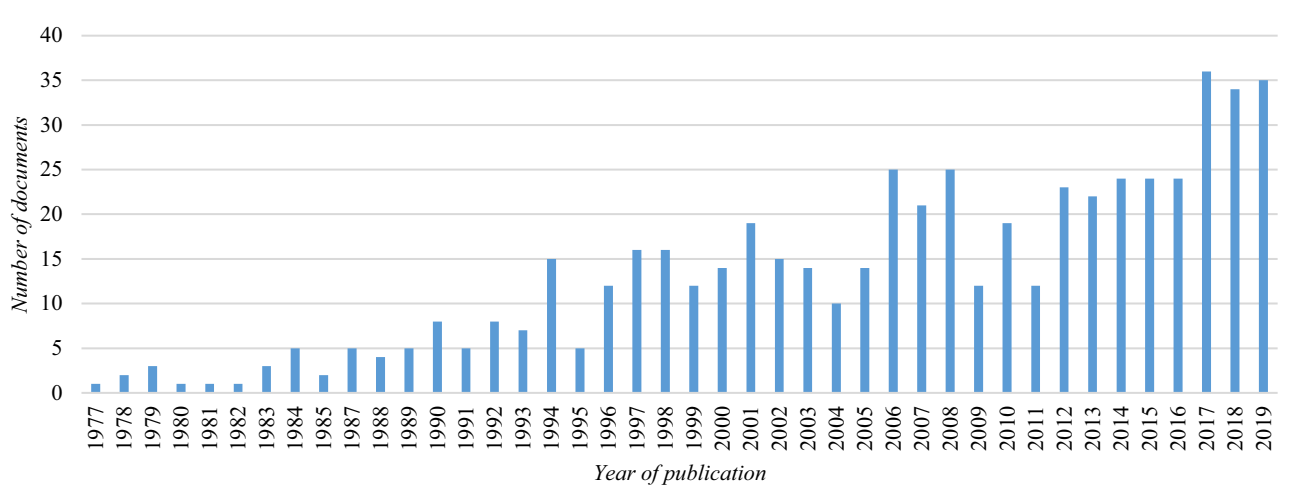


Table 1 Documents distribution and screening

\begin{tabular}{|c|c|c|c|c|c|c|}
\hline \multirow[b]{2}{*}{ Keywords } & \multicolumn{3}{|c|}{ Number of papers } & \multicolumn{3}{|c|}{ Number of relevant papers } \\
\hline & Scopus & Sciencedirect & Springer & Scopus & Sciencedirect & Springer \\
\hline "forging" AND "design to cost" & 9 & 56 & 10 & 3 & 9 & 0 \\
\hline "forging” AND "cost estimation" & 111 & 95 & 115 & 30 & 18 & 17 \\
\hline "forging" AND "production part costing" & 0 & 0 & 0 & 0 & 0 & 0 \\
\hline "forging" AND "should cost" & 0 & $\begin{array}{l}10153 \text { (no filter) } \\
233 \text { (filter to title, abstract or author) }\end{array}$ & 16 & 0 & 33 & 1 \\
\hline "forging" AND "activity-based costing" & 51 & 32 & 28 & 4 & 3 & 5 \\
\hline Total (not duplicated) & 559 & & & 85 & & \\
\hline
\end{tabular}

- Characterizing section: this section reported topics and trends related to the research's main focus, providing a score associated with the paper's contribution (ranging from 1 to 5 ) in this field. Topics were detailed in 5 categories to have a better insight into the contribution of each paper in a specific topic.
To answer the first research question (what are the most reliable cost analysis methods in the engineering design of forged components?), an overview of the cost estimation methods was carried out based on the classification proposed by Niazi et al. [19] and Salmi et al. [20]. This classification was used to create the ground for the cost analysis in forged component design.

Table 2 Categories for documents classification

\begin{tabular}{|c|c|}
\hline Category name & Category description \\
\hline \multicolumn{2}{|l|}{ General section } \\
\hline Main author & Corresponding author-name \\
\hline Other authors & Other authors name \\
\hline Title & Title of the reference \\
\hline Year & Year of the reference \\
\hline Type of publication & (i) Journal, (ii) Conference Proceeding, (iii) Conference Keynote, (iv) Technical Report, and (v) Thesis. \\
\hline Journal/Conference name & Name of the conference or the journal in which is published the reference \\
\hline Citations count & Number of citations that the article received from when it was published \\
\hline DOI & DOI number of the reference \\
\hline \multicolumn{2}{|l|}{ Specific section } \\
\hline Main objective of the paper & $\begin{array}{l}\text { The main objective of the reference. Example: open die forging of axisymmetric part; } \\
\text { closed die forging of aluminium shafts, etc. }\end{array}$ \\
\hline Related objectives & $\begin{array}{l}\text { Describe, if present, the other objectives in reference. Example: force and energy calculation; } \\
\text { use of Design for Manufacturing (DfM), etc. }\end{array}$ \\
\hline Novelty & The novelty in respect of the state of the art \\
\hline Results & The outcomes of the research method \\
\hline Limitation & $\begin{array}{l}\text { The limitations observed by the authors. For example, the reference is limited only to one } \\
\text { item of the forging process (heating, die cost, etc.), or is limited only to a particular } \\
\text { category of product (gear, shaft, etc.) }\end{array}$ \\
\hline \multicolumn{2}{|l|}{ Characterizing section } \\
\hline Topics & $\begin{array}{l}\text { The insights of the research: } \\
\text { T1 - Cost function and key parameters (Equation type, Input parameter string, Not Applicable) } \\
\text { T2 - Forging technology } \\
\text { o process (Closed-die, Open-die, Not Applicable) } \\
\text { o temperature (Cold, Warm, Hot, Not Applicable) } \\
\text { T3 - Material (Material class string, Material type string, Not Applicable) } \\
\text { T4 - CAD-linked method (YES, NO, Not Applicable) } \\
\text { T5 - CAE-linked method (YES, NO, Not Applicable) }\end{array}$ \\
\hline Importance & $\begin{array}{l}\text { The relevance of the reference concerning the objective of our review. Scale from } 1 \\
\text { to } 5 \text { based on the author judgment }\end{array}$ \\
\hline
\end{tabular}


Concerning the second research question (to what extent forging manufacturing knowledge has been used to derive numerical models and inputs for cost analysis methods?) three topics were identified: (T1) cost function and key parameters, (T2) forging technologies, and (T3) materials used in forging processes. These topics characterize the necessary knowledge to fulfil design requirements and develop reliable cost models [21, 22].

Concerning the third research question (to what extent virtual design tools have been investigated as potential inputs for cost analysis methods?), two topics were identified: (T4) CAD tool for geometrical inputs, and (T5) CAE tool process-related inputs. These topics reflect consolidated tools used in engineering departments aiming at the reliability of cost estimation output [23].

The identification of these topics allows defining the boundaries that contextualize the development of costrelated activities in the engineering design of forged components. Each relevant paper was then analyzed against the topics. The list of documents was reassessed concerning the topics mentioned earlier.

It is worth noting that due to the high number of papers retrieved by the literature analysis, they were clustered based on the common features discovered for each topic to have a general overview and a statistical distribution of the paper concerning these features. Afterward, based on the clusters, the most significant contributions were analyzed providing a discussion against the focus of this review. Thus, Section 3 reports the papers' classification based on the identified features and a description of the most significant contributions on the given topic.

\subsection{Bibliometric analysis}

The current study considers 85 papers, published in 42 different scientific journals or conference proceedings. The top nine journals $(21 \%)$, characterized by having at least two articles each one, cover 51 papers (60\%) out of 85 (Table 3). The documents of these nine journals have 810 citations (65\%) out of 1247. "Journal of Materials Processing Technology," "International Journal of Advanced Manufacturing Technology," and "CIRP Annals" are those academic journals with the highest number of papers and citations.

The most relevant subject areas of the nine most influential journals are summarized in Table 4 . It is noted that all the journals are Q1 for all the subject areas.

The most active countries on cost analysis of forged products are the USA and the UK (Table 5). North American and the UK researchers contributed with 39 papers (46\%), which have been cited 853 times (68\%). American and European researchers cover $76 \%$ of the published articles. It is worth highlighting that the quantity of cooperation among organizations is low (only eight papers have been jointly written by two or more researchers from different countries). The most cooperating countries are the USA ( 4 joint papers) and the UK (3 joint papers).

The most relevant universities researching this manuscript's topics (Table 6) belong to the most active countries.

\section{SLR framework: analysis and classification}

Among all manufacturing processes, forging technology has a particular emphasis because it helps to produce parts of superior mechanical properties with minimum material waste. In forging, raw material with simple geometry is plastically deformed by single or multiple steps into a product of relatively complex configuration [24]. An essential challenge for today's industry is increasing business profit by lowering the production costs and keeping optimal quality standards for the customer. This challenge could be faced by improving process efficiency (reducing non-compliant parts) and identifying the inefficiencies. Assessing product cost in the early phase of product design is crucial to ensure success in a competitive market. Engineering cost-based analysis was developed long ago. It consolidated over the years, providing a
Table 3 Most significant journals, with at least two papers (sorted according to the number of documents considered in the review)

\begin{tabular}{lll}
\hline Journals & Papers & Citations \\
\hline Journal of Materials Processing Technology & 21 & 309 \\
International Journal of Advanced Manufacturing Technology & 9 & 129 \\
CIRP Annals & 8 & 105 \\
Integrated Design and Manufacturing in Mechanical Engineering & 3 & 8 \\
International Journal of Machine Tools and Manufacture & 2 & 106 \\
Journal of Manufacturing Systems & 2 & 63 \\
Materials \& Design & 2 & 56 \\
Advances in Engineering Software & 2 & 29 \\
Digital Enterprise Technology & 2 & 5
\end{tabular}


Table 4 Most significant research topics, common to at least two journals

\begin{tabular}{ll}
\hline Topics & Quantity \\
\hline Industrial and manufacturing engineering & 5 \\
Mechanical engineering & 4 \\
Software & 3 \\
Computer Science applications & 2 \\
Control and systems engineering & 2 \\
\hline
\end{tabular}

general approach for manufacturing processes and ad-hoc methodologies referring to a given technology. This is the case of cost-based analysis in developing a forging component that is considered in this review. Several classification methods of cost approaches already exist in cost modelling literature. Salmi et al. [20] proposed a classification method of cost approaches based on three aspects: (i) phase of applicability, (ii) granularity level, and (iii) approach type.

The first classification reflects the design phase in which cost models are used: early and late design [25]. According to the cost estimate's data availability, a cost model can be classified concerning the applicability phase. In early design, cost models can predict cost during a pre-processing step, thus anticipating the production system, which is still under the arrangement and not yet implemented. In the case of late design, the models aim to estimate the production cost generated by a system that exists and is well or exhaustively known. The second classification divides models into top-down and bottom-up approaches. The top-down is principally based on historical data from previous works and projects are used [26]. The bottom-up requires estimation of resources cost rates for

Table 5 Most active countries, with at least two papers (sorted according to the number of documents considered in the review)

\begin{tabular}{lll}
\hline Countries & Papers & Citations \\
\hline USA & 24 & 581 \\
UK & 15 & 272 \\
France & 8 & 58 \\
Germany & 7 & 35 \\
Iran & 6 & 66 \\
Italy & 4 & 20 \\
India & 3 & 42 \\
Sweden & 3 & 18 \\
Turkey & 3 & 45 \\
China & 2 & 36 \\
Japan & 2 & 11 \\
Korea & 2 & 2 \\
South Korea & 2 & 173 \\
Spain & 2 & 28 \\
Taiwan & 2 & 7 \\
\hline
\end{tabular}

Table 6 Most active universities, with at least three papers (sorted according to the number of documents)

\begin{tabular}{lll}
\hline Universities & Papers & Citations \\
\hline University of Strathclyde (UK) & 4 & 53 \\
Ohio State University (USA) & 3 & 143 \\
Bu-Ali Sina University (IRN) & 3 & 22 \\
Università Politecnica delle Marche (ITA) & 3 & 10 \\
\hline
\end{tabular}

each element and sub-element of work. This classification was overcome by the third one, which classifies models in two leading families: (i) qualitative methods, based on comparative analysis of a new product and an existing one and, (ii) quantitative methods, based on a detailed analysis of product design, including its features and corresponding manufacturing processes [7, 19, 27-29]. Qualitative cost estimation methods include knowledge-based and intuitive methods grounded on the estimator's experience and, analogical methods based on the manufacturing process similarity between the product to be designed and products previously estimated [19]. Quantitative cost estimation methods include analytical methods, based on primary tasks decomposition, feature-based methods, which use geometric features as the basis for cost estimation and, parametric methods founded on the relations between product characteristics and their cost [30].

Campi et al., [31] compare the different techniques with three assessment levels: low, medium, and high. The comparison is based on five features: accuracy, robustness, scalability, uncertainty, and subjectivity. Accuracy reflects the confidence level of the methodology results concerning the actual cost provided by the company. Robustness addresses the adaptation of the method with product features (e.g., dimensions, geometry, tolerances). Scalability measures how much the technique is suitable for different production sets and technologies. Uncertainty reports the sensitivity of a given method based on the input parameters. Subjectivity addresses the dependency of the technique from the expertise and knowledge of the end-user. Qualitative methods require expert knowledge to generate a cost evaluation, and their replicability is limited. Qualitative methods are mostly used during the initial phase of product design (conceptual design), due to the lack of complete design information in the early stages of a project [32]. To cope with this issue and to improve the performance in terms of accuracy and consistency, new techniques including statistical techniques and machine learning method (CBRcase-based reasoning and ANNs - artificial neural networks) were introduced $[33,34]$. Data from the past projects are used to train, test, and validate the built model's performance. Qualitative methods' weaknesses lie in the difficulty in handling many variables (cost-driven parameters) and the 
requirement for establishing a cost function between inputs and outputs by regression analysis methods [35].

Quantitative cost estimation methods are mostly used in the late stage of product design (embodiment design and detail design), targeting the manufacturing domain and the supply chain management to achieve an accurate cost estimation with the possibility to increase the level of granularity present in their models [32]. Quantitative methods are robust and accurate because assessment uses a product decomposition structure to collect cost factors associated with production processes and morphological components' features [35]. As a general outcome, in forging technology, quantitative methods are the most suitable choice for assessing product costs during the design phase [31]. The literature highlighted the importance of knowledge management in the evaluation of product cost, in particular in the definition of two key factors: (i) cost models and relationships for the assessment, and (ii) input parameters [36]. Cost variability is approximately $\pm 15 \%$ compared to the actual cost [37].
Qualitative cost estimation methods for forged products were limited investigated within the literature ([38-42]). The available model for the cost estimation of forged components is often inaccurate for a comparative analysis due to the missing items related to the forging process. Indeed, many authors focused only on a specific phase (or an item) in the forging process. Table 7 summarizes the distribution of works based on cost estimation methods. Concerning the quantitative approach, different models were developed based on the process's characteristics. Analytical and parametric models are the most widespread and are well distributed over the years. Knight et al. and Campi et al. developed analytical cost models for the closed-die and the open-die forging, respectively $[31,53]$. Both methods provided a cost estimation of a forged component using material type and the forged dimensions as input data. The forging process was divided into various cost items: material, heating, labour, machine costs, and in the case of the closed-die also the die and flash removal costs.

Table 7 Documents distribution based on cost estimation method (in brackets the number of documents per category)

\begin{tabular}{|c|c|c|c|}
\hline \multirow[t]{2}{*}{ Cost estimation method main category } & \multicolumn{3}{|c|}{ Cost estimation method sub-category } \\
\hline & Analytical (26) & Parametric (8) & Featured based (4) \\
\hline Quantitative methods (37) & $\begin{array}{l}{[43]} \\
{[44]} \\
{[31]} \\
{[45]} \\
{[46]} \\
{[47]} \\
{[48]} \\
{[49]} \\
{[50]} \\
{[51]} \\
{[52]} \\
{[53]} \\
{[54]} \\
{[55]} \\
{[56]} \\
{[57]} \\
{[58]} \\
{[59]} \\
{[60]} \\
{[61]} \\
{[62]} \\
{[34]} \\
{[63]} \\
{[64]} \\
{[65]} \\
{[66]} \\
\text { Analooical (1) }\end{array}$ & Intuitive (-) & $\begin{array}{l}{[73]} \\
{[38]} \\
{[56]} \\
{[74]} \\
\\
\\
\text { Knowledoe based (4) }\end{array}$ \\
\hline Qualitative methods (5) & $\begin{array}{l}\text { Analogical (1) } \\
{[38]}\end{array}$ & $\begin{array}{l}\text { Intultive (-) } \\
-\end{array}$ & $\begin{array}{l}\text { Knowledge based (4) } \\
{[39]} \\
{[40]} \\
{[41]} \\
{[42]}\end{array}$ \\
\hline
\end{tabular}


By following the result of this classification, quantitative methods are more spread among researchers and practitioners. The result analysis shows how quantitative methods, particularly the analytical ones, can catch the peculiarities of this process and how the cost features can be linked with the information available at the early design phase. Quantitative methods are less subjective and replicable for different components, and they provided numerical results that allow comparing different solutions. Moreover, as described in various works, parameters and equation can be updated to consider more aspects (i.e., additional operations, detailed geometrical information, process constraints) for a more accurate result and understanding of the cost distribution. The possibility to refine the estimation method is significant for forged components due to the following aspects: (i) the process can vary from a few to several steps, (ii) dimensions of machines and equipment need to be selected based on product size/shape and specific process constraints (i.e., hot, cold forming), and (iii) geometrical parameters are essential in the definition of the number of strokes as well as in the design of specific equipment. These methods require dedicated cost models (function) and cost parameters (input) for their definition. These models are driven by each particular technology, the material type, geometrical information, and process inputs. All these topics are analyzed and discussed in the following subsections.

\subsection{Cost function and key input parameters}

Cost function and key input parameters were largely analyzed and used in the cost analysis of forged components, in particular for quantitative methods (i.e., analytical and parametric models). This first topic of the analysis identifies the type of equation used for the cost assessment and the main input parameters that characterize the cost model. A cost model consists of various data, rules, and equations organized according to a specific framework [75]. The cost estimation process originates from a set of cost-driver. A cost driver is defined as the independent variable responsible for cost variation in a cost estimation relationship [63]. Cost-drivers for manufacturing cost estimation can be clustered into several cost items: (i) material, (ii) machine, (iii) labour, (iv) equipment, (v) consumables, and (vi) energy [75].

The review highlighted the most common cost-drivers in forging cost estimation models. For example, the forging $m a-$ terial type $\left(M_{f}\right)$ is the most widespread cost driver in qualitative and quantitative cost estimation models, as reported in Table 8 . The reason why this driver is of great importance deals with the information it contains; indeed, the forging material type shows both raw material cost and physical attributes that can affect the manufacturing process (e.g., forging temperature, strain rate, etc.). The forging material affects the raw material cost and the cost of labour and machine for operations (cutting, heating, forging), and the equipment cost (die cost). A material with lower forgiability (e.g. nickel alloys) requires higher temperatures, higher energy, and load compared to more forgeable material (e.g. aluminium), increasing then the final costs $[31,44,45,48,53,54]$. Forging material type also impacts the equipment cost; indeed, it affects the die life, and consequently, the maintenance operations $[53,54]$.

In some works, these drivers are replaced by the volume of the forged part $\left(V_{f}\right)$ which affects not only the raw material category cost but also the forging load/energy required to deform the part [67]. In some cases, the $V_{f}$ parameter is used as the main cost driver to calculate the total cost of a forged part $[37,51,72] . V_{f}$ is also used to assess the forging load/energy necessary to deform the part and, consequently, choose the forging machines [31]. The forging energy/load can also be determined by using the plan or projected area of the forged part $\left(A_{p f}\right)[45,53,54]$, which is the projection of the part on the forging plane. Having determined the forging machine, the machine unitary cost $\left(c_{m c}\right)$, together with the labour unitary $\operatorname{cost}\left(c_{l}\right)$, and the energy cost $\left(c_{e}\right)$, are used to calculate the cost related to the machine item [31, 44, 45, 48, 51, 53, 54]. Always concerning to the geometric characteristics of the forged component, dimensions $\left(d_{f}\right)$, (length $\left(l_{f}\right)$, width $\left(w_{f}\right)$, height $\left(h_{f}\right)$, thickness $\left(t_{f}\right)$ and shape $\left(s_{f}\right)$ (e.g., axisymmetric, prismatic) are used as cost drivers, since they affect the overall process time $[31,38,39,40,42,45,46,47,48,66,67,73]$ and the die cost (die material cost and die manufacturing cost) $[53,54,68]$.

Only a few works were focused on the size of production, including in their model costs drivers such as batch size $\left(B_{f}\right)$ and the production volume $\left(P V_{f}\right)$, which affect, respectively, the setup time [31, 44, 59], and the equipment cost (die cost) $[50,53,54]$. Less widespread as cost drivers are the forged part feature $\left(F_{f}\right)$ (e.g., hole, bosses, ribs) [34, 42, 55, 66].

Table 8 summarizes the contributions in defining the key parameters for cost models concerning the equation type used in the cost model. The equations are classified into five categories:

1. linear with one variable at a time: the model is based on one or more first-order equations that consider only one cost driver for each equation at a time.

2. linear with more variables at a time: the model is based on one or more first-order equations that consider two or more cost drivers for each equation at a time.

3. non-linear with one variable at a time: the model is based on one or more equations that are higher/lower-order than first, and only one cost driver is considered for each equation at a time.

4. non-linear with more variables at a time: the model is based on one or more equations that are higher/lower- 
Table 8 Documents distribution based on cost estimation method together whit equation category and cost drivers

\begin{tabular}{|c|c|c|}
\hline Author & Equation type & Cost drivers \\
\hline \multicolumn{3}{|c|}{ Analytical (26) } \\
\hline$[43]$ & linear with one variable & $M_{d}$ \\
\hline$[44]$ & linear with one variable & $M_{f}, V_{f}, c_{m c}, c_{b}, d_{f}, s_{f}, B_{f}$ \\
\hline$[31]$ & not linear with one variable & $M_{f}, V_{f}, c_{m c}, c_{l}, M_{t}, d_{f}, s_{f}, A_{p f}, B_{f}, P M I$ \\
\hline$[45]$ & not linear with one variable & $M_{f}, V_{f}, d_{f}, s_{f}, A_{p f}$ \\
\hline$[46]$ & linear with one variable & $M_{f}, V_{f}, d_{f}, s_{f}, B_{f}, P M I$ \\
\hline [47] & linear with one variable & $M_{f}, V_{f}, d_{f}, s_{f}, B_{f}, P M I$ \\
\hline$[48]$ & N.A. & $M_{f}, V_{f}, d_{f}, s_{f}, B_{f}$ \\
\hline [49] & linear with one variable & N.A. \\
\hline$[50]$ & N.A. & $M_{d}, V_{d}, P V_{f}$ \\
\hline$[51]$ & linear with one variable & $M_{f}, V_{f}, d_{f}, s_{f}$, \\
\hline$[52]$ & linear with one variable & N.A. \\
\hline$[53]$ & not linear with more variables & $M_{f}, V_{f}, c_{m c}, c_{l}, M_{t}, d_{f}, s_{f}, A_{p f}, B_{f}, P V_{f}, F_{f}, P M I, T_{f}$ \\
\hline$[54]$ & not linear with more variables & $M_{f}, V_{f}, c_{m c}, c_{l}, M_{t}, d_{f}, s_{f}, A_{p f}, B_{f}, P V_{f}, F_{f}, P M I, T_{f}$ \\
\hline$[55]$ & $N . A$. & $M_{f}, V_{f}, d_{f}, B_{f}, P V_{f}, F_{f}, P M I$ \\
\hline$[56]$ & N.A. & $M_{f}, V_{f}, d_{f}, s_{f}, F_{f}$ \\
\hline$[57]$ & N.A: & $c_{m c}, c_{l}, c_{e}, M_{t}, s_{f}, B_{f}$ \\
\hline$[58]$ & N.A. & $M_{f}, d_{f}, s_{f}, F_{f}, P M I, T_{f}$ \\
\hline$[59]$ & linear with one variable & $M_{f}, V_{f}, M_{t}, B_{f}, P V_{f}, P M I$ \\
\hline$[60]$ & N.A. & $M_{f}, V_{f}, d_{f}$ \\
\hline$[62]$ & N.A. & $M_{f}, V_{f}, d_{f}$ \\
\hline$[34]$ & N.A. (neural network) & $M_{f}, M_{d}, d_{f}, s_{f}, F_{f}, P M I$ \\
\hline$[63]$ & linear with one variable & $M_{f}, V_{f}, c_{m c}, c_{l}, c_{e}, B_{f}$ \\
\hline$[64]$ & linear with one variable & $M_{f}, V_{f}, c_{m c}, c_{l}, c_{e}, B_{f}$ \\
\hline$[65]$ & not linear with one variable & $M_{f}, V_{f}, d_{f}, s_{f}$ \\
\hline$[66]$ & linear with one variable & $M_{f}, V_{f}, d_{f}, s_{f}, B_{f}, P V_{f}, P M I$ \\
\hline \multicolumn{3}{|c|}{ Parametric (8) } \\
\hline$[67]$ & linear with more variables & $M_{f}, V_{f}, M_{t}, d_{f}, s_{f}$ \\
\hline$[68]$ & not linear with one variable & $M_{d}, W_{d}, V_{f}, s_{f}$ \\
\hline [69] & not linear with one variable & $s_{f}, A_{p f}, B_{f}, P V_{f}$ \\
\hline$[70]$ & linear with more variables & $M_{f}$ \\
\hline$[37]$ & linear with one variable & $M_{f}, V_{f}, s_{f}$ \\
\hline$[71]$ & N.A. (neural network) & $M_{f}, d_{f}, s_{f}$ \\
\hline$[72]$ & linear with one variable & $M_{f}, V_{f}, s_{f}$ \\
\hline$[32]$ & $N . A$. & $M_{f}, V_{f}, d_{f}, s_{f}$ \\
\hline \multicolumn{3}{|c|}{ Featured based (4) } \\
\hline$[73]$ & N.A. & $M_{f}, V_{f}, d_{f}, s_{f}, F_{f}, P M I$ \\
\hline$[38]$ & N.A. & $M_{f}, d_{f}, s_{f}, P M I$ \\
\hline$[56]$ & N.A. & $M_{f}, V_{f}, d_{f}, s_{f}, F_{f}$ \\
\hline$[74]$ & N.A. & $M_{f}, V_{f}, d_{f}, F_{f}, P M I$ \\
\hline \multicolumn{3}{|c|}{ Analogical (1) } \\
\hline$[38]$ & $N . A$. & $M_{f}, d_{f}, s_{f}, P M I$ \\
\hline \multicolumn{3}{|c|}{ Intuitive (-) } \\
\hline- & - & - \\
\hline \multicolumn{3}{|c|}{ Knowledge based (4) } \\
\hline [39] & N.A. & $M_{f}, d_{f}, s_{f}, P M I$ \\
\hline$[40]$ & N.A: & $M_{f}, d_{f}, s_{f}, P M I$ \\
\hline$[41]$ & N.A. & $M_{f}, V_{f}, d_{f}, s_{f}, B_{f}, P V_{f}, F_{f}, P M I$ \\
\hline$[42]$ & linear with one variable & $M_{f}, d_{f}, s_{f}, F_{f}, P M I$ \\
\hline
\end{tabular}


order than first and two or more cost drivers are considered for each equation at a time.

5. Not applicable (N.A.): the equation was not reported, or none of the above categories is applicable (e.g. adoption of neural networks or genetic algorithms).

In all cases, the total cost is achieved by the sum of the results for each equation.

As highlighted by this classification, the use of linear and non-linear equations (supported by single or multiple variables) seems to be the most accurate approach to develop a robust cost analysis in designing forged components. Forging material type (Mf) is undoubtedly the most crucial driver in the cost assessment when a single variable is adopted. However, other drivers can be used to refine the final result, such as the volume of the forged part (Vf), component dimensions $(d f)$, and shape $(s f)$. These additional drivers are fundamental when the part presents a complex shape or when the die is needed (i.e., closed die forging). The outcomes mentioned above are of interest when developing a specific model for cost analysis of forged parts.

\subsection{Forging technologies}

Forging uses hammers or presses to squeeze and deform the raw material (billet) into a high strength part. According to [76], forging processes include (i) open-die forging, (ii) closed-die forging with flash (conventional), (iii) closed-die forging without flash (precision), (iv) coining, (v) rotary (orbital) forging, (vi) radial forging, (vii) electro-upsetting, (viii) hobbing, (ix) isothermal forging, (x) nosing, (xi) metal powder forging, and (xii) upsetting and incremental forging. Rolling, extrusion, and drawing processes were not addressed in any work analyzed for this review. The open die forging process allows manufacturing components with large dimensions and optimal mechanical properties. Open die forging is generally used for simple shape components [77] such as shafts, rings, disks, bushings, end caps and shells [78]. On the other hand, in closed-die forging, the metal piece is compressed in an enclosed die impression to obtain a near-netshape part. The process temperature classifies the technology in hot-forging, warm, and cold-forging [79]. Different features can be obtained applying hot, warm and cold forging and they are summarized in Table 9. For example, cold forging allows to reach high-precision dimensions with great surface quality [82]. On the other hand, only workpieces with limited weight/ dimension can be processed. Hot and warm forging are less precise in terms of tollerances, a larger machining allowance is needed and they usually require subsequent machining processes (including finishing processes).

As a first result, the SLR highlights how many documents were focused on the closed-die process (60 articles). Only a few authors addressed open-die forging (4 papers).
Table 9 comparison of forging processes (based on temperature) excerpt of [80]

\begin{tabular}{llll}
\hline Product feature & Forging process & & \\
\cline { 2 - 4 } & Hot forging & Warm forging & Cold forging \\
\hline Workpiece weight & $0.05-1500 \mathrm{~kg}$ & $0.001-50 \mathrm{~kg}$ & $0.001-30 \mathrm{~kg}$ \\
Precision & IT 13-IT 16 & IT 11-IT 14 & IT 08-IT 11 \\
Quality surface (Rz) & Up to 50 $\mu \mathrm{m}$ & Up to $30 \mu \mathrm{m}$ & Up to $10 \mu \mathrm{m}$ \\
Forming cost [81] & Up to $113 \%$ & $100 \%$ & Up to $147 \%$ \\
Machining required & High & Low & Very low \\
\hline
\end{tabular}

Concerning the remaining papers, cost models were performed without considering a specific technology. Referring to the process temperature, a different distribution of works was noticed in the literature analysis. In particular, 52 documents were developed for hot forging, 13 were developed for the cold process, while only five papers referred to a warm cycle. It is worth noting that process temperature (warm and cold forging) was not addressed under the umbrella of opendie forging, powder forging, and radial forging, which belong to hot processes.

Among the several processes belonging to closed-die forging, Gronostajski et al. state that the development of the modern die forging industry will be directly related to the development of precision forging [78]. In this case, the geometrical accuracy limits the material consumption and the machine's occupation while improving the mechanical properties. Machining costs are usually negligible for cold forging, a near-net-shape process requiring a lower amount of raw material [83]. Generally, closed-die cold forging allows better surface roughness and tight tolerances than hot forging. However, cold forging causes higher wear of the dies, and then a shorter life, concerning the hot forging. Thus, in cold forging is demonstrated that an essential item for cost analysis is the cost of the die/equipment $[43,50,68]$, which is a combination of other drivers such as the die material $\left(M_{d}\right)$ and the die volume $\left(V_{d}\right)$, as mentioned in the previous chapter. The review also shows how in cold forging, and in general in closed die forging, the batch size $\left(B_{f}\right)[44]$ and the production volume $\left(P V_{f}\right)$ significantly affect the choice of the process type $[50,53,54]$. The items mentioned above are considered critical parameters for evaluating the die cost's importance in each manufactured part.

Moreover, the setup time is another crucial driver directly connected to the number of steps required to perform the overall process. As shown for some case studies (i.e., a steering yoke), the cold forging process allows reaching the necessary accuracy requirement and the possibility to avoid a subsequent machining process about the hot forging [84]. Thus, beyond the geometric characteristics of the part, such as dimensions $\left(d_{f}\right)$ and shape $\left(s_{f}\right)$, the forged part features $\left(F_{f}\right)$ 
(e.g., hole, bosses, ribs) and the product manufacturing information (PMI) (tolerances and roughness) constitute a fundamental pillar for the definition of a closed-die cost model. Precision hot forging in respect of conventional forging allows better material utilization, reduced cost of cutting (flash removal), and the integration of heat treatment in the process [85]. While cold forging is used with common, non-ferrous alloys, low carbon and low alloy steels, warm forging is used for medium carbon, high alloy steels and more complex shapes [86]. This outcome reflects the fact that different materials have different forgeability, which affects temperatures, energy and load required for deformation, and then the cost of labour, the cost of machine for operations (cutting, heating, forging) and the equipment cost (die cost). Case studies referring to the cost estimation of warm forged parts are mainly simple geometries such as flanged cylinders $[87,88]$ and bevel gears $[85,89]$.

On the other hand, the cost analysis of open-die forging technology was debated by two recent works $[31,72]$. Campi et al. proposed an analytical model that uses as input the part's geometrical features to calculate the time and the cost required for the process. Martinelli et al. developed a parametric cost model for a specific family of forged components (discs of a gas turbine). Both approaches tried to cover the gap highlighted by other works, encompassing all the phases required to perform the forging process (i.e., cutting, heating, and upsetting). Similarly, Harzendorf et al. studied the manufacturing costs of a wind turbine where the shaft is produced by open die forging technology [51]. In this specific case, the cost model tackles the material cost related to the raw material, without providing a detailed definition of all the other cost items involved in the manufacturing process.

Few works were focused on cost estimation of forging technologies different than closed- and open-die (i.e., powder forging). Powder forging is a process in which an unsintered, presintered, or sintered powder metal preform is forged in a confined or trapped die [76]. The powder forging process has a lower level of precision and roughness than precision forging but higher than conventional closed-die hot forging [90]. According to Altan et al., powder forging has virtually no material waste and produces near-net-shape products [91]. However, metal powder is more expensive compared to conventional materials. Nakagawa et al. use machining chips as material and powder forging to reduce the cost of a hot-forged drive flange achieving the same mechanical properties of part manufacturind with bulk material [62]. Although the powder forging process is usually more expensive than conventional techniques, the part manufactured with this process allows a cost reduction of approx. $25 \%$ thanks to the following aspects: (i) the cost of the chip is less expensive (1/3 of the bulk material), and (ii) a less amount of material is used. Table 10 summarizes document distribution in terms of forging technology (both process and temperature).
Based on this overview related to the forging technologies and the relation to the manufacturing cost assessment, it is possible to conclude that forging technology does not affect the cost model's choice. Indeed, there is a random distribution of papers developed by using different quantitative models (i.e., analytical, parametric and feature-based). However, even if the model's choice is not essential with the type of forging, the selection of cost-drivers to include in the model is characterized by the process. Some cost-drivers are common to all technologies and cost models, such as the material, the geometric features of the part, and the product manufacturing information (PMI). The main difference between the analyzed technologies recalls the use of these parameters for the cost calculation. For closed-die forging, due to the importance of the die cost, geometrical inputs such as dimensions (df), shape (sf), forged part features ( $\mathrm{Ff}$ ) (e.g., hole, bosses, ribs), as well as PMI (tolerances and roughness), play a critical role. On the other side, for open-die forging, forging material type (Mf) is the key parameter. At the same time, geometrical inputs are used to assess the machine occupation and process time.

\subsection{Material}

The forging material influences the design of the forged piece and the selection of the forging process. This third topic of the analysis deals with characterising the influence of the material type on the cost analysis and how this driver affects the overall model accuracy. According to some authors, the material generally accounts for more than $50 \%$ of the manufacturing cost of a forged component including material waste in the form of flash and scale losses $[32,53,54,60]$. Besides, the material affects the forgiability, which represents the ability of a metal to deform without failure, regardless of the magnitude of load and stresses required for deformation. The forgiability influences the design of the forging part and the parameters of the entire forging process. Material affects draft angle, tolerances, web-thickness, allowances, and other design characteristics [48]. As discussed in the previous Section 3.1 the forging material type $(\mathrm{Mf})$ is the most widespread cost driver used in developing the cost estimation model.

Each material has a specific forging temperature and requires a given time to achieve the desired temperature; thus, the heating time cost is affected by material [31]. For example, considering a steel stock with a diameter less than $75 \mathrm{~mm}$, the heating time necessary to reach the set temperature for $25 \mathrm{~mm}$ of piece length should be approximately 5 minutes for lowcarbon and medium-carbon steels and around 6 minutes for low-alloy steels [76]. Material forgiability affects the magnitude of load necessary to deform the piece and then the cost of this operation. To evaluate the influence of material on load/ force required for piece deformation, generally, authors use multiplying/load factors $[45,53,54]$ or strain rate strength [31]. Although the material is a crucial parameter in the final 
Table 10 Documents distribution based on forging technology (in brackets the number of documents per category)

\begin{tabular}{|c|c|c|c|}
\hline \multirow[t]{2}{*}{ Forging process } & \multicolumn{3}{|c|}{ Forging temperature } \\
\hline & Hot forging (37) & Warm forging (2) & Cold forging (-) \\
\hline \multirow[t]{38}{*}{ Closed die forging conventional (39) } & {$[92]$} & {$[93]$} & \\
\hline & {$[83]$} & {$[89]$} & \\
\hline & {$[93]$} & {$[86]$} & \\
\hline & [91] & & \\
\hline & {$[67]$} & & \\
\hline & {$[43]$} & & \\
\hline & {$[44]$} & & \\
\hline & {$[73]$} & & \\
\hline & {$[94]$} & & \\
\hline & {$[95]$} & & \\
\hline & {$[96]$} & & \\
\hline & {$[45]$} & & \\
\hline & {$[46]$} & & \\
\hline & {$[47]$} & & \\
\hline & {$[48]$} & & \\
\hline & {$[97]$} & & \\
\hline & {$[98]$} & & \\
\hline & [99] & & \\
\hline & {$[90]$} & & \\
\hline & {$[50]$} & & \\
\hline & {$[100]$} & & \\
\hline & {$[101]$} & & \\
\hline & {$[102]$} & & \\
\hline & {$[103]$} & & \\
\hline & {$[104]$} & & \\
\hline & {$[53]$} & & \\
\hline & {$[54]$} & & \\
\hline & {$[55]$} & & \\
\hline & {$[57]$} & & \\
\hline & {$[105]$} & & \\
\hline & {$[84]$} & & \\
\hline & {$[106]$} & & \\
\hline & [107] & & \\
\hline & {$[108]$} & & \\
\hline & {$[74]$} & & \\
\hline & [109] & & \\
\hline & {$[110]$} & & \\
\hline & Hot forging (13) & Warm forging (3) & Cold forging (13) \\
\hline \multirow[t]{14}{*}{ Closed die forging (precision) (25) } & {$[93]$} & {$[93]$} & {$[116]$} \\
\hline & [91] & {$[85]$} & {$[83]$} \\
\hline & [111] & {$[87]$} & [93] \\
\hline & {$[112]$} & & {$[68]$} \\
\hline & [69] & & {$[90]$} \\
\hline & {$[70]$} & & [103] \\
\hline & [85] & & {$[117]$} \\
\hline & [104] & & [118] \\
\hline & [113] & & [84] \\
\hline & [58] & & {$[87]$} \\
\hline & [114] & & [119] \\
\hline & {$[115]$} & & {$[65]$} \\
\hline & {$[74]$} & & {$[86]$} \\
\hline & Hot forging (4) & Warm forging (-) & Cold forging (-) \\
\hline \multirow[t]{5}{*}{ Open die forging (4) } & {$[31]$} & - & - \\
\hline & {$[51]$} & & \\
\hline & {$[72]$} & & \\
\hline & {$[74]$} & & \\
\hline & Hot forging (1) & Warm forging (-) & Cold forging (-) \\
\hline Radial forging (1) & {$[56]$} & - & - \\
\hline
\end{tabular}


Table 10 (continued)

\begin{tabular}{|c|c|c|c|}
\hline \multirow[t]{2}{*}{ Forging process } & \multicolumn{3}{|c|}{ Forging temperature } \\
\hline & Hot forging (37) & Warm forging (2) & Cold forging (-) \\
\hline & Hot forging (5) & Warm forging (-) & Cold forging (-) \\
\hline Powder forging (5) & $\begin{array}{l}{[91]} \\
{[47]} \\
{[90]} \\
{[62]} \\
{[86]}\end{array}$ & - & - \\
\hline
\end{tabular}

cost assessment, cost models described in the previous sections were developed independently from the material used to manufacture the part. For this reason, the cost models are mostly applicable to all types of materials used in the forged industry. However, some case studies were reported in the literature analysing the effect of a specific material in the cost estimation model. For example, $\mathrm{Yu}$ et al. developed a cost estimation method of forged parts manufactured with aluminium alloys [66]. This dedicated model examined the challenges in aluminium process selection, such as material workability. The classification of materials used for the case studies described within the analyzed papers was carried out on the same subject. In particular, most of the case studies were focused on carbon steel and aluminium alloy. In contrast, few articles were focused on superalloy (titanium or nickel alloy) or even more exotic materials. This outcome is related to the prevalence of forged components made by carbon steel and aluminium alloy. Table 11 reports the classification of works based on the material used for the case study.

As highlighted by this classification, the material is the characteristic feature to consider in the forged component design and reliable cost analysis. Despite the raw material accounts for more than $50 \%$ of the manufacturing cost and it affects many items of the cost model (i.e., material, machine, equipment and energy), cost models do not require to be adapted for each specific material. This is an interesting outcome retrieved by the literature review about this topic.

\subsection{CAD-linked method-use of product shape and geometry inputs}

The product shape and geometry of the forged component affect many items of the forging process, such as the amount of material, the forces required for material deformation, or the cost of the die. From the literature analysis, it appears that a critical aspect for the development of a cost model is the product geometry. Indeed, it is challenging to build a model valid for any shape and geometry. Therefore, many studies focus on a particular type of forged component, such as axisymmetric components [31, 44, 97-99, 120], prismatic components [73], components with double T sections [65], or even cup-shaped part [121]. Most of the analyzed works focused on axisymmetric components due to their limited complexity compared to others. Axisymmetric features can be simplified by considering only two dimensions, thanks to their symmetry [31].

In other cases, the cost models were defined for a specific type of component which has the same features in terms of shape and geometry, such as connecting rod [91], gear [85, 89, 111], shaft [37, 51, 113], blade/airfoil [71, 92, 112, 115], turbine disc [72], flange nut [114], spindle [104], flywheel [112], and bracket $[57,62]$. The clustering of shapes and geometries in a specific component allowed more accurate cost models starting from the same geometrical information. Table 12 reports papers clustering concerning the shape and the type of component analyzed within the paper.

As a general outcome of the literature review related to this topic, cost models are sensitive to the shape and the geometry

Table 11 Material distribution in case studies (in brackets the number of documents per category)

\begin{tabular}{ll}
\hline Category & Documents \\
\hline Steel alloy (12) & {$[43]$} \\
& {$[46]$} \\
& {$[51]$} \\
& {$[103]$} \\
& {$[121]$} \\
& {$[58]$} \\
& {$[84]$} \\
& {$[87]$} \\
Aluminium alloy(4) & {$[62]$} \\
& {$[89]$} \\
& {$[119]$} \\
Superalloy and other materials (4) & {$[65]$} \\
& {$[91]$} \\
& {$[50]$} \\
& {$[100]$} \\
& {$[113]$} \\
& {$[66]$} \\
& {$[92]$} \\
& {$[94]$} \\
& {$[47]$} \\
\end{tabular}


of the product under analysis. Indeed, product geometry affects several cost items such as machine and equipment. The forging time required to produce the part is strongly related to the shape and the time necessary to perform auxiliary operations (i.e., heating, cutting, machining). It would be beneficial from a technical point of view to link product features with the analysis of CAD models used to derive geometric information (data input) [122]. This practice will permit to fill up the cost models with geometrical inputs automatically. Thus, the link with the CAD model seems an efficient solution to minimize designers' effort about the accuracy of the results. This is a useful tip retrieved by the literature review about this topic.

\subsection{CAE-linked method-use of simulation output}

The ever-increasing costs of material, energy, and especially workforce require that forging processes and tooling be designed and developed with a minimum amount of trial and errors with the shortest possible lead time. Therefore, the application of computer-aided techniques, i.e., CAM, CAE, and, especially, FEA-based computer simulation is a mandatory task when a forged part is designed. Implementing this technique requires a thorough knowledge of the principal variables of the forging process and their interactions. The first examples of finite element method applied to forged components and coupled with cost analysis appeared before 2000 when the FEA systems and tools have been consolidated in
Table 12 Documents distribution based on the shape of forged part (in brackets the number of documents per category)

\begin{tabular}{|c|c|c|}
\hline Shape category & Component type & Documents \\
\hline \multirow[t]{3}{*}{ Multi-shape (3) } & \multirow[t]{3}{*}{ General (3) } & {$[45]$} \\
\hline & & {$[53]$} \\
\hline & & {$[54]$} \\
\hline \multirow[t]{19}{*}{ Axisymmetric (19) } & \multirow[t]{8}{*}{ General (8) } & {$[44]$} \\
\hline & & {$[31]$} \\
\hline & & {$[97]$} \\
\hline & & {$[98]$} \\
\hline & & [99] \\
\hline & & {$[120]$} \\
\hline & & {$[32]$} \\
\hline & & {$[108]$} \\
\hline & \multirow{3}{*}{ Gear (3) } & [111] \\
\hline & & {$[85]$} \\
\hline & & [89] \\
\hline & \multirow[t]{4}{*}{ Shaft (4) } & {$[51]$} \\
\hline & & {$[56]$} \\
\hline & & {$[37]$} \\
\hline & & [113] \\
\hline & Turbine discs (1) & {$[72]$} \\
\hline & Flange nut (1) & {$[118]$} \\
\hline & Spindle (1) & {$[104]$} \\
\hline & Flywheel (1) & {$[112]$} \\
\hline \multirow[t]{4}{*}{ Prismatic (4) } & General (1) & {$[73]$} \\
\hline & \multirow[t]{2}{*}{ Bracket (2) } & {$[57]$} \\
\hline & & {$[62]$} \\
\hline & Connection rod (1) & {$[91]$} \\
\hline Double T sections (1) & General (1) & [65] \\
\hline Cup-shaped part (1) & General (1) & {$[121]$} \\
\hline \multirow[t]{4}{*}{ Freeform part (4) } & \multirow[t]{4}{*}{ Blade/Airfoil (4) } & {$[92]$} \\
\hline & & [71] \\
\hline & & [115] \\
\hline & & [114] \\
\hline
\end{tabular}


the engineering departments of manufacturing companies [ 44 , $50,58,85,100-102,108,114,119,123]$. An interesting application of CAE for cost estimation was provided by developing commercial finite element software (DEFORM) to determine the best fillet radius for formability [58]. Several candidate processes (forging plus machining steps) were selected for evaluation in an economic decision matrix to define the best configuration (process) according to the cost. Berlioz et al. developed a CAE simulation tool based on quasi-static evolution of metal flow and deformation. It was used for cost estimation of components realized with closed-die forging technology [44]. The system was focused only on axisymmetric parts and based on component size and shape, calculating the geometric features needed for forging, such as draft angles, machining allowance, flashes, and fillet radii. The developed tool simulates the part deformation during the forging process, estimating force and energy required by the hammer, which is essential information about the process's cost as discussed previously. All the calculated parameters using the FEA tool were then transferred to the cost estimation model to assess product cost. More often, CAE tools were used for the structural analysis of the die, to estimate the useful life which also has an impact on the manufacturing cost $[84,91,101,102$, 115].
However, when FEM and FEA tools were coupled with the process analysis, the component's cost assessment assumed a secondary role within the research. Table 13 summarizes all documents where the CAE tool was used specifying the scope of FEM/FEA optimization, and the part type or the shape analyzed.

The literature review analysis referred to this topic highlights how simulation tools (i.e., CAE tools) are consolidated in the forging industry. It allows predicting the material flow and deformation during the process. These aspects are related to the cost, such as the machine and equipment cost items. However, the simulation process's output was not used as an input parameter for the cost models. This outcome shows how cost analysis in the early design phase requires inputs closer to the design requirements than engineering activity results. Thus, the CAE systems are usually used downstream of the cost assessment for process optimization.

\section{SLR results}

Following the outcomes of the literature review, different considerations can be done. First of all, several works attempt to

Table 13 List of documents which discuss CAE (in brackets the number of documents per category)

\begin{tabular}{|c|c|c|c|}
\hline Documents & CAE type & Used for & Forged part type/shape \\
\hline [91] & FEM/FEA & Preform design and tooling concept & Connecting rod \\
\hline [111] & FEM/FEA - CAM & Forged part design and forging load & Gear \\
\hline [112] & FEM/FEA & Component form errors-design, elastic analysis of part and die design & Flywheel \\
\hline$[44]$ & CAE generic & Forging load & Axisymmetric components \\
\hline$[70]$ & CAE generic & Energy consumption & Not a specified type or shape \\
\hline [85] & FEM/FEA & Forging load, design of the part and design of the die & Bevel gear \\
\hline$[50]$ & FEM/FEA & Forging load and heating time & Connecting road \\
\hline$[100]$ & FEM/FEA & Forged part design & Knuckle arm \\
\hline$[120]$ & FEM/FEA & Forged part design & Wheel \\
\hline$[101]$ & FEM/FEA & Die design & Not a specified type or shape \\
\hline$[102]$ & FEM/FEA & Flow simulation and die design & Not a specified type or shape \\
\hline$[58]$ & FEM/FEA & Forging load and forged part design & Bracket \\
\hline [84] & FEM/FEA & Forging load and forged part design & Steering yoke \\
\hline [114] & FEM/FEA & Preform part design and forging load & Aerofoil sections \\
\hline$[115]$ & FEM/FEA & Die design & Aerofoil sections \\
\hline$[89]$ & FEM/FEA & Preform part design & Bevel gear \\
\hline [119] & FEM/FEA & Forged part design & Outer race \\
\hline$[65]$ & FEM/FEA & Forged part design and forging load & I-beam \\
\hline [108] & CAE generic & Forging load & Axisymmetric components \\
\hline [123] & FEM/FEA & Preform die design & H shaped parts \\
\hline
\end{tabular}


cope with cost analysis in the forging industry covering a wide range of applications and related aspects (e.g. product geometries, process simulation, metallurgy, technology). This topic started to be debated long ago, as reported by different works developed at the end of the "70s. The literature review results were analyzed against the three research questions identified within this review's primary objective.

Concerning the first research question-What are the most reliable cost analysis methods in the engineering design of forged components? - based on the definition of Niazi et al. [19], cost models are classified in quantitative vs qualitative. The literature analysis showed how quantitative methods are dominant compared with the qualitative ones (36 and 5, respectively). The rationale behind this outcome is the quantitative models' accuracy that usually offer lower uncertainty and better correspond with the actual costs. Among the quantitative methods, analytic models were described in 25 papers. In comparison, parametric and feature-based models were presented respectively only in 9 and 3 articles. Cost drivers of each model were identified, allowing to define most essential criteria for early cost estimation of forged components. According to [75], a cost model could be organized through a specific framework which classifies costs into six categories: (i) material, (ii) machine, (iii) labour, (iv) equipment, (v) consumables, and (vi) energy. The most important criteria for developing a forging cost model refers to the material used for the part and the geometrical features of the part itself. Forging material type $\left(\mathrm{M}_{\mathrm{f}}\right)$ is undoubtedly the input parameter necessary to compute costs of forged parts from review analysis. The forging material affects the raw material cost and the cost of labour, the cost of machine for manufacturing operations (cutting, heating, forging) and the equipment cost (die characteristics, as material and dimensions are in-fact a function of part material type). The others essential factors to compute costs are referred to part geometry: the volume of the forged part $\left(V_{f}\right)$, the projected area of the forged part $\left(A_{p f}\right)$, dimensions $\left(d_{f}\right)$, (length $\left(l_{f}\right)$, width $\left(w_{f}\right)$, height $\left(h_{f}\right)$, thickness $\left.\left(t_{f}\right)\right)$, and shape $\left(s_{f}\right)$. Through this information, it is possible to define the cost of the material, the types and dimensions of the machines (then their hourly costs) and the duration of the operations. Other cost drivers useful for calculating the cost, actually less used in literature are: the batch size $\left(B_{f}\right)$, the production volume $\left(P V_{f}\right)$, which affect respectively setup time and equipment cost (die cost), the labour unitary cost $\left(c_{l}\right)$, and the machine unitary cost $\left(c_{m c}\right)$. A more in-depth insight into the cost models revealed how analytic models appear more robust and lower uncertainty than the parametric ones. The most important models to compute the cost would be identified in the analytical category. Most complete models are from [31, 53, 54], which cover all the most crucial cost drivers previously identified. Others important models of this category are from [44, 46, 47, 59, 66], which cover the large part of previous cost drivers. Also interesting is the cost model provided by Rehman et al. 1998 (belonging to knowledge-based approaches). Often not all of the cost drivers previously identified are present in the early phases. Parametric cost models seem to be more suitable for early design stages (i.e. conceptual design) when the available information is limited with a low level of detail. From a parametric point of view, the most interesting models are provided by [67-69] and [32]. On the other side, analytic models reached a high level of maturity. They are usually coupled with CAD information (e.g., shape, size, dimensions, tolerances), which feed the model's cost parameters. Besides, analytical models could be used to calculate other design requirements (e.g., environmental indicators). Feature of the parts and their properties could be related to dedicated indices (i.e., environmental impact indices as $\mathrm{CO} 2$ emissions), calculated through analytical models. However, the uncertainty characterization of results and how to consider uncertainty for the decisionmaking process during the design of forged components is still an open issue.

Concerning the second research question-To what extent forging manufacturing knowledge has been used to derive numerical models and inputs for cost analysis methods? - the following outcomes were retrieved. Cost-based approaches developed in the early ' 80 s tried to address closed-die forging technology because shapes and geometries created with this manufacturing process are well-defined and known. For this reason, the cost estimation models were developed based on product shape, and considering the main cost items affected by the shape (e.g., raw material costs, die costs, process costs). The evolution of cost estimation approaches over the years has involved two main aspects: (i) the analysis of more complex shapes and geometries for the closed-die forging and, (ii) the adoption of different models for open-die forging but limited to simple geometries (i.e., axisymmetric parts). However, the representativeness of these works is limited compared with other technologies (i.e., casting) [30, 124-127]. Indeed, the number of papers developed on this topic suffers from different issues that can be summarized as follow:

- Open die-forging technology has a limited volume of production and less predictable process sequence (e.g., the number of strokes) compared with other traditional technologies (i.e., casting), making it challenging to develop a generic approach and model for cost estimation.

- Forging technologies, like many other manufacturing technologies, has had significant technological progress and innovation, which is spread within experts and insiders of the industrial world but hidden in the scientific community, probably due to confidentiality reasons of the components produced (high-performance components for strategic sectors such as oil and gas, aerospace and army).

- The multidisciplinary requirements of modern forging technology combined with the cost of laboratory infrastructures and the significant amount of time spent to produce high- 
quality research publications are the main reasons for discouraging researchers from working in this field.

- Forging technologies allow the production of highperformance components. This manufacturing process is used only in those cases when performances are more important than costs.

- Forging technologies are incredibly complex manufacturing processes, and the level of automation varies between produced components. In some cases, (e.g., open die forging of axisymmetric parts), the process is characterized by a low level of automation, while in other cases (e.g., cold forging or precision forging), the process is hugely automatized. This cause the impossibility to reach standardized cost models that can be used for different components or shapes.

A more in-depth insight into the specific technologies (i.e., closed-die forging, open-die forging, hot-forging, and cold/warm-forging) has been presented with different trends over the years. Closed-die forging showed an asymptotic trend which reveals the right level of maturity of cost estimation methods and tools for this process. Researchers derived a limited interest from cold/warm-forging since only a few attempts were discovered in the literature (15 papers in total). The reasons behind this gap are (i) the limited development of the process, and (ii) the difficulties in the prediction of process parameters which are strongly related to material deformation, and distortion. Indeed, this kind of process requires knowledge from multiple disciplines such as engineering design, metallurgy, and process simulation (technology). Materials were analyzed in different methods, focusing on those mainly used in forging such as steel alloy (12), aluminium alloy (4), superalloy, and other materials (4).

Concerning the third research question-To what extent virtual design tools have been investigated as potential inputs for cost analysis methods? - the following outcomes were retrieved. Even if consolidated design tools (i.e., CAD, CAE) are primarily adopted in design departments, some issues about using these tools for cost analysis are still present. The first one is the real integration of manufacturing process simulation with cost analysis and cost estimation. Besides, the possibility to use cost estimation results for the implementation of Design-to-Cost actions is still an uncovered area. Open-die forging showed an exponential trend with most of the works confined in the last years. It gained particular relevance for researchers with unexplored areas for future research activities connected with cost and design activities. The gap for this latter technology is related to the characterization of machines and presses to perform the process based on the product features (mainly shape, size, dimensions, and tolerances) and the definition of process steps including the sequence of operations necessary to obtain the final piece. On the other hand, the definition of the initial geometry and sizes (raw material) was well debated in the literature. Forging process simulation seems to be the most interesting and promising solution to develop more reliable cost estimation results. Indeed, coupling CAD modelling, process simulation, and cost assessment, it is possible to gain a higher level of details to assess manufacturing costs and, thus, to apply Design-toCost strategies and reduce the overall cost of the process early in the design phase. The CAD model is the input of software tools for process simulation (e.g., FEM, CFD). Their output is the input for cost assessment tools, providing a virtuous cycle to perform a better product design. So doing, virtual prototyping is the link of the chain between design and manufacturing. The characterization of output parameters and cost models need to be developed as well.

Evolution analysis of cost-related activities in the design of forged components was done to investigate future research potential. The synthesis of this content, obtained from the text analysis results on the qualitative insights and the corresponding quantitative data, is presented in Fig. 3. In particular, Fig. 3 shows (i) the relevance of the estimated topic - reflected by the size of the bubbles, (ii) the research topic share (RTS) reflecting the impact within the horizontal axis, and (iii) the research topic growth potential (RTGP)—reflecting the need for further research within the vertical axis.

The size of bubbles illustrates the total number of publications for each specific topic within the period investigated. RTS is calculated by dividing the number of publications of the particular topic within the last decade (2010-2019) by the total number of publications considering the overall review objective. RTGP is calculated by applying the least mean square method with the number of publications per topic and year during the last 10 years. The use of the previous 10 years for calculating the RTS indicator reflects the initial breakdown of the analysis in four decades, considering a decade a reasonable period of observation for this analysis.

The least mean square used to compute the RTGP indicator allows catching the overall trend of topics over the years. The formula used for calculating the RTGP is reported in Eq. 1:

$R T G P=\frac{\sum X_{i} \sum Y_{i}-n \sum X_{i} Y_{i}}{\left(\sum X_{i}\right)^{2}-n \sum\left(X_{i}\right)^{2}}$

where:

- $X_{i}$ is the $i$-th year of publication ( $i$-th is the index for the reference period-from 2010 to 2019)

- $Y_{i}$ is the number of papers published within the $i$-th year $(i-$ th is the index for the reference period-from 2010 to 2019)

- $n$ is the overall number of years in the period of analysis (10 [years])

Tables 14 and 15 summarized the data used for the calculation of RTS and RTGP indicators. 
Fig. 3 Classification of research topics for future potential and researches

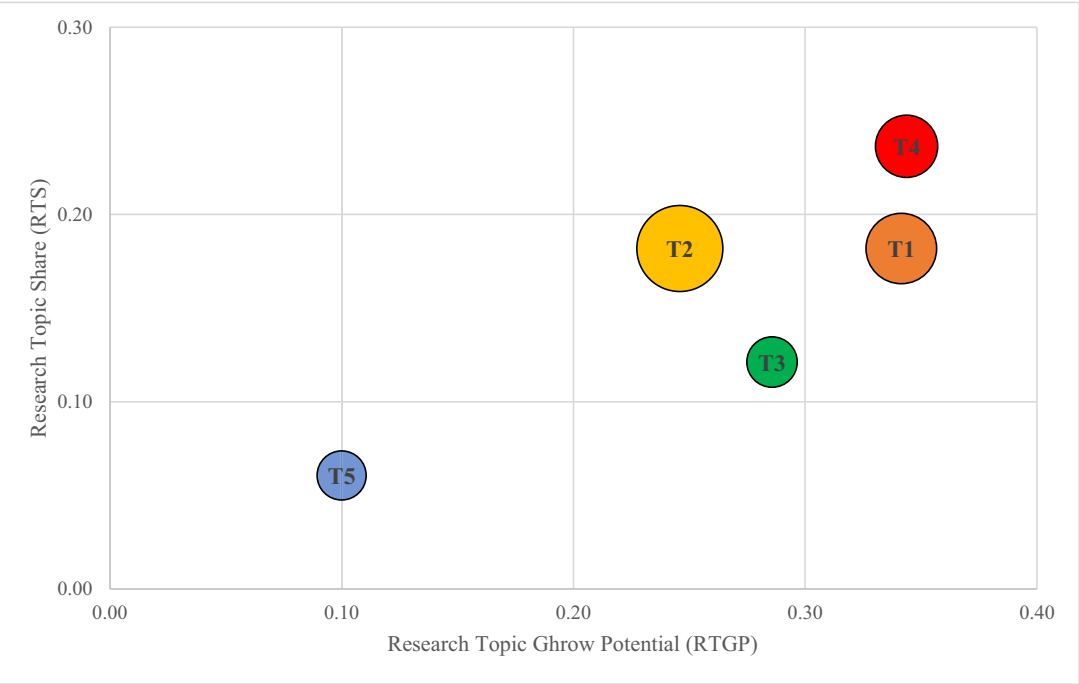

By applying the mentioned equations and the graphical representation obtained by developing a bubble chart, it is possible to divide the map into two main areas. The upperright part of the graph reflects topics needing further investigation and has received consideration within the literature. The bottom-left part of the chart demonstrates topics that have not been well considered throughout the literature and have low potential growth as they do not have the scientific community's interest.

Results from Fig. 3 highlighted how the upper-right part of the graph is the most populated. This outcome suggests how most of the five topics (T1, T2, and T4) were well addressed through recent publications. However, they still need further developments and improvements. Looking at each specific topic, T1 (cost function and key parameters) reflects tremendous importance considering the overall number of publications and considering the research potential growth. It means that the models and the driven parameters used to estimate and characterize the cost are critical aspects of the design and development of forged products. The technical evolution of this topic is mainly based on analytical and parametric models where the definition of cost functions moves towards nonlinear equations that seem to be more reliable and able to close the gap in the accuracy between the estimated and the real result. Adopting a single variable at a time and multiple drivers (including the geometrical one) also seems beneficial to this aim.

Some lacks are present within the literature, and further investigation by the research community is required for this topic.

Referring to topic T2 (forging technologies), the type of process received the most significant importance considering the overall number of publications. Again, T2 is close to the upper-right area of the graph. It has good potential for further investigation, recalling that forging technology is an essential feature in characterising cost activities when a designer approaches a forged product. The technical evolution of the works shows how emerging technologies (i.e., precision forging) are gaining more interest, as well as the possibility to capture the engineering knowledge for consolidated technologies (i.e., open die forging) where this knowledge is tacit and spread among employers and technical figures inside the company. Topic T3 (material) has limited potential for further investigation; however, this topic requires a more in-depth analysis. Indeed, the overall number of publications recalling this topic is low and looking at the RTGP indicator (Fig. 4), it is possible to notice that even if the trend is increasing over the years, this is not statistically significant due to the overall
Table 14 Research topic share (RTS) data

\begin{tabular}{lllr}
\hline Topic & $\begin{array}{l}\text { Overall number of papers } \\
\text { (years 1977-2019) }\end{array}$ & $\begin{array}{l}\text { Number of papers in the last } \\
\text { decade (years 2010-2019) }\end{array}$ & RTS \\
\hline T1 Cost function and key parameters & 41 & 14 & 0,34 \\
T2 Forging technology & 61 & 15 & 0,25 \\
T3 Material & 21 & 6 & 0,29 \\
T4 CAD-linked method & 32 & 12 & 0,34 \\
T5 CAE-linked method & 20 & 2 & 0,10 \\
\hline
\end{tabular}


Table 15 Research topic growth potential (RTGP) data

\begin{tabular}{|c|c|c|c|c|c|c|c|c|c|c|c|}
\hline \multirow[t]{2}{*}{ Topic } & \multicolumn{10}{|c|}{ Number of papers per year } & \multirow[t]{2}{*}{ RTGP } \\
\hline & 2010 & 2011 & 2012 & 2013 & 2014 & 2015 & 2016 & 2017 & 2018 & 2019 & \\
\hline T1 Cost function and key parameters & 1 & 0 & 1 & 1 & 2 & 0 & 3 & 3 & 1 & 2 & 0,18 \\
\hline T2 Forging technology & 1 & 1 & 1 & 0 & 2 & 0 & 1 & 5 & 1 & 2 & 0,18 \\
\hline T3 Material & 0 & 1 & 0 & 0 & 0 & 0 & 1 & 2 & 2 & 0 & 0,12 \\
\hline T4 CAD-linked method & 1 & 0 & 1 & 0 & 0 & 0 & 2 & 3 & 2 & 2 & 0,24 \\
\hline T5 CAE-linked method & 0 & 0 & 0 & 0 & 0 & 0 & 1 & 0 & 1 & 0 & 0,06 \\
\hline
\end{tabular}

Fig. 4 RTGP indicator for the five topics
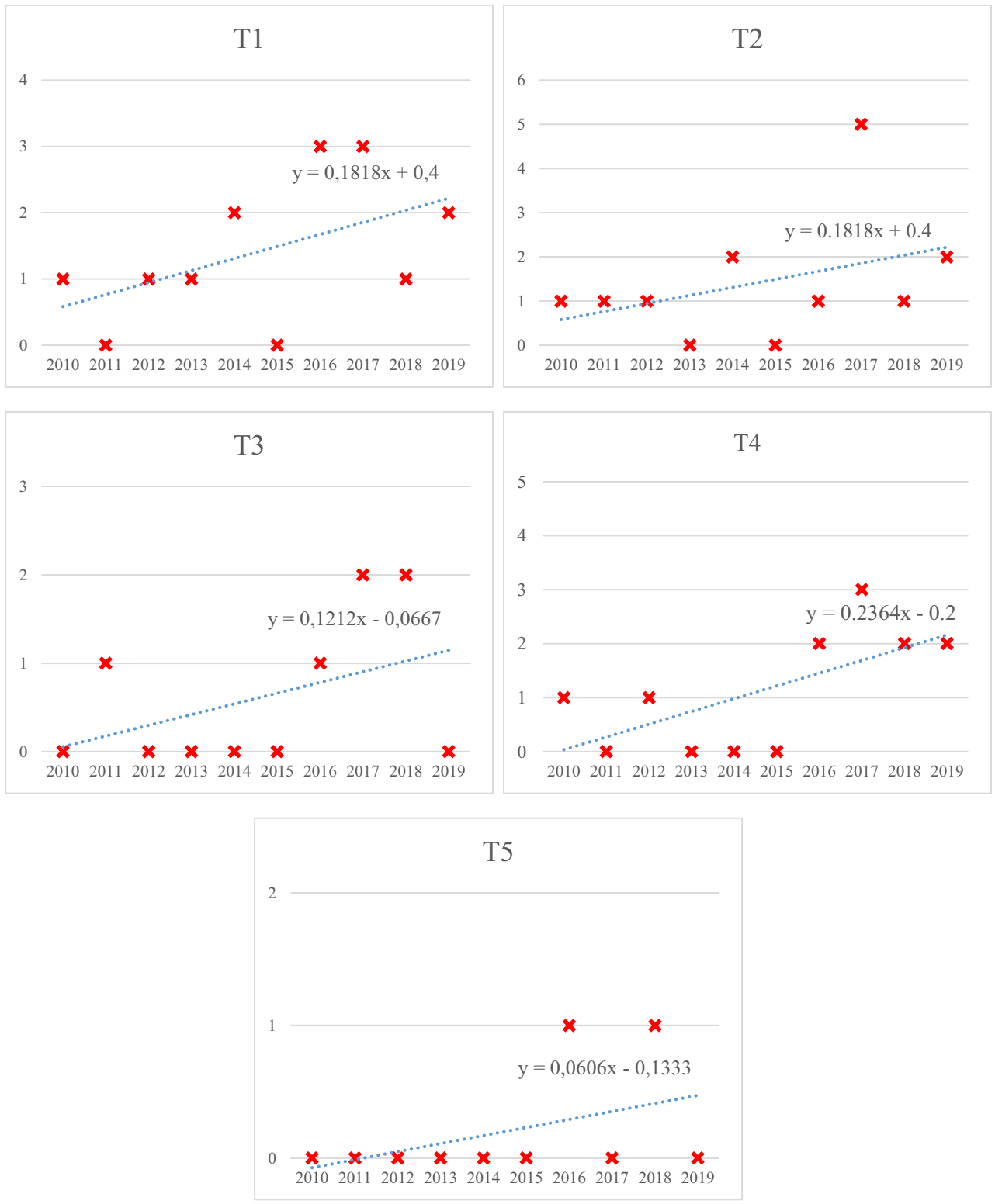
number of publications which is very low for this topic. From a technical point of view, only specific applications (i.e., case studies) were recently developed concerning this topic. This outcome reveals how T3 is a topic with potential interest for researchers and practitioners looking at the development of forging components and their implications on cost activities, even if the relevance of this topic was very low in the last decade.

Considering the topics T4 (CAD-linked method) and T5 (CAE-linked method), they present approximately the same relevance within the literature (similar bubble size) but the opposite impact (RTS). They need further investigation (RTGP). The location of T4, in the top-right corner of the graph, represents a fascinating research topic with high potential growth. It means that CAD is still a key tool in the development of mechanical components manufactured with forging technology, and the information available from CAD models affect the definition of cost items and cost accuracy. The technical evolution of this topic refers to the possibility of adding more geometrical data in the cost model to have a more accurate result. Moreover, the opportunity to couple the two tools (CAD and cost estimation) is another relevant evolution of this topic for developing an integrated environment in Design for Manufacturing.

Conversely, it seems that T5, located on the bottom-left corner of the graph of the analysis for future research growth potential, lost researchers' interest concerning this review's objective compared to other topics. It means that the CAE result does not bring additional inputs in assessing the cost for this specific sector. Besides, looking at the RTGP indicator (Fig. 4), the number of papers published in the last decades about this topic is deficient. This outcome of the literature review contrasts with the results highlighted within the analyzed documents. The CAE tool was depicted as critical to cope with data accuracy and reliability of results in the cost analysis of forged products. However, from the technical point of view, the difficulty of reinjecting the knowledge gained by the simulation process into the cost analysis does not significantly benefit the accuracy of the cost analysis results.

\section{Conclusions}

The paper aims to critically review the design and engineering activities oriented to cost analysis and cost estimation of mechanical components realized by the forging technology. During the literature review, 85 research items were analyzed, including 65 journal papers, 18 conference proceedings, and 2 conference keynotes covering a broad timeframe (from 1977 to 2019).

The literature review was conducted to collect relevant trends (topics) on this primary objective, giving deep insight into the main contributions to the research and future perspectives for researchers and companies/manufacturers. Topics were defined based on the technical issues summarized by the three research questions used to guide the review and retrieved by the practical needs of practitioners in this field. The SLR provides an overall framework supporting costrelated activities in developing complex products that require to be manufactured by forging.

Referring to the first research questions, quantitative methods, and analytical and parametric ones are the most reliable cost analysis methods in the engineering design of forged components. Among quantitative methods, analytical methods are more spread than parametric and feature-based ones (respectively 25 vs 9 vs 3 ). Analytical models provide better performances than other methods in terms of accuracy, robustness, scalability, and uncertainty. The adoption of analytical models allows achieving an accurate cost estimation to increase the level of granularity. Indeed, using a product decomposition structure, cost items associated with production processes can be included or neglected based on the type of assessment and the available information (i.e., the design process phase). Besides, the analytical methods allow knowing the share of each cost item described within the model.

Referring to the second research question, manufacturing knowledge is considered the main driver in the definition of numerical models and inputs for cost analysis methods. Few drivers were identified as the key parameters to include in the cost model, such as the forging material type (Mf), the volume of the forged part (Vf), component dimensions (df), and shape (sf). These cost-drivers are responsible for the robustness and reliability of the cost model (no matter if it is linear or non-linear). In contrast, other cost-drivers can be included to refine the model and to increase the level of confidence of the model, reducing the gap between the estimated and the actual one. Case studies were well debated in the literature (i.e., gears, shaft, turbine discs, flange nuts, spindles, brackets, and blades) showing that forging cost models work well for products with similar geometrical features. Several attempts were made from the same product family to generalize the model based on the geometry analogies (e.g., axisymmetric parts, prismatic parts). However, due to the specificity of geometries realized with forging processes, cost models seem not to be completely generalized, creating a tool that can develop any component independent from the geometry. Thus, handling component geometry for predicting costs in the early design phase remains an open issue in this field. Outcomes from the 3D modelling such as geometry, shape, volume, dimensions, and additional manufacturing information (i.e., tolerances and roughness) need to be clustered to provide the basis for developing numerical models for more accurate costs analyses and reliable results of cost estimation.

Referring to the third research question, virtual design tools were mostly investigated as potential inputs for the cost analysis method. However, several lacks were retrieved conducting this review. The first one is establishing a better cost evaluation using CAD features such as the parametrization of cost items concerning the technology and design 
parameters. Indeed, the link between the design parameters of forged components and the forging processes' technological features was not adequately addressed. Another outcome is related to the adoption of engineering tools (i.e., CAE) coupled with the analysis of cost during the product development of forged components. CAE analysis results can be reinjected as input parameters of the cost model to fit better the process and all the aspects related to the manufacturing costs. However, this latter shows some limitations since simulation results need further manipulation before being entered as input parameters in the cost analysis model. Moreover, CAE simulation is usually a subsequent task referring to the cost assessment phase.

In conclusion, there are still some open points that can be further investigated by researchers in the field of a cost analysis of forged components. The first one refers to developing innovative models for a robust assessment of cost starting from reliable approaches (i.e., analytical and parametric). As also noticed in other manufacturing fields, parametric models, such as machine learning, can be adopted to develop innovative tools to capitalize on past experiences and avoid design mistakes. These approaches will translate implicit (tacit) knowledge into explicit knowledge that can be used for cost analysis and implemented into Design-to-Cost and Design-for-Manufacturing tools. Indeed, knowledge engineering in the forging context is still a critical issue. The second one refers to the geometrical data input (cost-drivers and parameters); even if additional costdrivers count less than $10 \%$ in the accuracy of the model, the possibility to create an integrated design environment where design tools (i.e., CAD tool) and cost estimation tool are linked is of great interest for the academic and industrial world. A gap in available solutions is noticed with this review.

List of acronyms $3 D$, three dimensional; $A B C$, activity-based-costing; $A N N s$, artificial neural networks; $A_{p f}$, plan or projected area of the forged part; $B_{f}$, batch size; $C A D$, computer aided design; $C A E$, computer-aided engineering; $C A M$, computer-aided manufacturing; $C B R$, case-based reasoning; $c_{e}$, energy cost; $C F D$, computational fluid dynamics; $c_{l}$, labour unitary cost; $c_{m c}$, machine unitary cost; $d_{f}$, forged dimensions; $D f A$, design for assembly; $D f M$, design for manufacturing; $D f M A$, design for manufacturing and assembly; $D f X$, design for X; $D O I$, digital object identifier; $D t C$, design to cost; $E D M$, economic decision matrix; FEA, finite element analysis; FEM, finite element method; $F_{f}$, forged part feature; $h_{f}$, forged height; $l_{f}$, forged length; $M_{d}$, die material; $M_{f}$, forging material; $M_{t}$, forging machine type; $P M I$, product and manufacturing information; $P V_{f}$, production volume; $R T G P$, research topic growth potential; RTS, research topic share; $s_{f}$, component shape; SLR , systematic literature review; $T 1$, topic $1 ; T 2$, topic $2 ; T 3$, topic $3 ; T 4$, topic $4 ; T 5$, topic $5 ; t_{f}$, thickness; $V_{d}$, die volume; $V_{f}$, forged volume; $w_{f}$, forged width

Author contribution Conceptualization: Michele Germani Marco Mandolini; Methodology: Claudio Favi, Federico Campi, Irene Martinelli; validation: Michele Germani; formal analysis: Federico Campi; Claudio Favi; investigation: Federico Campi, Irene Martinelli; resources: Michele Germani, Marco Mandolini; data curation: Federico Campi; writing - original draft preparation: Claudio Favi, Federico
Campi; writing-review and editing: Marco Mandolini, Irene Martinelli; supervision: Michele Germani.

Funding Open access funding provided by Università degli Studi di Parma within the CRUI-CARE Agreement.

Data availability The authors declare that datasets are hosted in public repositories.

\section{Declarations}

Ethics approval The manuscript was not submitted to other journals for simultaneous consideration.

The submitted work is original and was not published elsewhere in any form or language (partially or in full).

Results are presented clearly, honestly, and without fabrication, falsification or inappropriate data manipulation (including image based manipulation).

No data, text, or theories by others are presented as if they were the author's own ('plagiarism').

No conflicts of interest are present

The research was not developed involving Human Participants and/or Animals for experiments.

All authors have read and agreed to the published version of the manuscript.

The authors declare no conflict of interest

Consent to participate All authors voluntarily agree to participate in this research study

Consent to publication The authors give the consents to publish the manuscript.

Competing interests The authors declare no competing interests.

Open Access This article is licensed under a Creative Commons Attribution 4.0 International License, which permits use, sharing, adaptation, distribution and reproduction in any medium or format, as long as you give appropriate credit to the original author(s) and the source, provide a link to the Creative Commons licence, and indicate if changes were made. The images or other third party material in this article are included in the article's Creative Commons licence, unless indicated otherwise in a credit line to the material. If material is not included in the article's Creative Commons licence and your intended use is not permitted by statutory regulation or exceeds the permitted use, you will need to obtain permission directly from the copyright holder. To view a copy of this licence, visit http://creativecommons.org/licenses/by/4.0/.

\section{References}

1. Xu L, Li Z, Li S, Tang F (2007) A decision support system for product design in concurrent engineering. Decis Support Syst 42(4):2029-2042

2. Magrab EB, Gupta SK, McCluskey FP, Sandborn PA (2009) Integrated product and process design and development, 2nd edn. CRC Press

3. Ficalora JP, Cohen L (2009) Quality function deployment and six sigma: A QFD handbook 2nd edition. Prentice Hall

4. Boothroyd G, Dewhurst P, Knight WA (2011) Product design for manufacture and assembly, 3rd edn. CRC Press 
5. Michaels JV, Wood WP (1989) Design to cost. WileyInterscience

6. Ben-Arieh D, Qian L (2003) Activity-based cost management for design and development stage. Int J Prod Econ 83(2):169-183. https://doi.org/10.1016/S0925-5273(02)00323-7

7. H'mida F, Martin P, Vernadat F (2006) Cost estimation in mechanical production: The Cost Entity approach applied to integrated product engineering. Int J Prod Econ 103(1):17-35. https://doi. org/10.1016/j.ijpe.2005.02.016

8. Behrens B-A, Bouguecha A, Lüken I, Klassen AD, Odening D (2014) 3.16 - near-net and net shape forging. In: Hashmi S, Batalha GF, Van Tyne CJ, Yilbas B (eds) Comprehensive materials processing. Elsevier, pp 427-446. https://doi.org/10.1016/ B978-0-08-096532-1.00323-X

9. My CA, Le CH, Packianather M, Bohez ELJ (2019) Novel robot arm design and implementation for hot forging press automation. Int J Prod Res 57(14):4579-4593

10. Berviller L, Bigot R, Martin P (2006) Technological information concerning the integrated design of "net-shape" forged parts. Int J Adv Manuf Technol 31:247-257. https://doi.org/10.1007/s00170005-0203-x

11. Hawryluk M (2017) Review of selected methods of increasing the life of forging tools in hot die forging processes. Arch Civ Mech Eng 16(4):845-866

12. Widomski P, Gronostajski Z (2020) Comprehensive Review of Methods for Increasing the Durability of Hot Forging Tools. Procedia Manufac 47:349-355

13. Gronostajski Z, Kaszuba M, Hawryluk M, Zwierzchowski M (2014) A review of the degradation mechanisms of the hot forging tools. Arch Civ Mech Eng 14(4-5):528-539

14. Politis DJ, Politis NJ, Lin J, Dean TA (2018) A review of force reduction methods in precision forging axisymmetric shapes. Int $\mathrm{J}$ Adv Manuf Technol 97:2809-2833

15. Hawryluk M, Ziemba J, Sadowski P (2017) A review of current and new measurement techniques used in hot die forging processes. Meas Control 50(3):74-86

16. Chen F, Cui Z, Chen J (2014) Prediction of microstructural evolution during hot forging. Manuf Rev 2014:1(6)

17. Nahrmann M, Matzenmiller A (2020) A critical review and assessment of different thermoviscoplastic material models for simultaneous hot/cold forging analysis. Int J Mater Form

18. Wang A, He F (2004) A review of developments in the forging of connecting rods in China. J Mater Process Technol 151(1-3):192195

19. Niazi A, Dai JS, Balabani S, Seneviratne L (2005) product cost estimation: technique classification and methodology review. J Manuf Sci Eng 128(2):563-575

20. Salmi A, David P, Blanco E, Summers JD (2016) A review of cost estimation models for determining assembly automation level. Comput Ind Eng 98:246-259

21. Ashby M. 2010 Materials selection in mechanical design. Butterworth-Heinemann, 4th edition

22. Ulrich KT, Eppinger SD (2011) Product design and development, McGraw-Hill Education, 5th edition

23. Chang K-H (2013) product manufacturing and cost estimating using CAD/CAE. Academic Press 1st edition

24. Altan T, Ngaile G, Shen G (2005) Cold and hot forging: fundamentals and applications. ASM International

25. Ping L, Yongtong H, Bode J, Shouju R (1996) Multi-agent system for cost estimation. Comput Ind Eng 3(3-4):731-735

26. Stewart RD (1991) Cost estimating, 2nd edn. Wiley-Interscience, New York

27. Cavalieri S, Maccarrone P, Pinto R (2004) Parametric vs. neural network models for the estimation of production costs: A case study in the automotive industry. Int J Prod Econ 91(2):165-177
28. Duverlie P, Castelain JM (1999) Cost estimation during design step: parametric method versus case based reasoning method. Int J Adv Manuf Technol 15(12):895-906

29. Layer A, Brinke ET, Houten FV, Kals H, Haasis S (2002) Recent and future trends in cost estimation. Int J Comput Integr Manuf 15(6):499-510

30. Chougule RG, Ravi B (2006) Casting cost estimation in an integrated product and process design environment. Int $\mathrm{J}$ Comput Integr Manuf 19(7):676-688

31. Campi F, Favi C, Mandolini M, Germani M (2019) Using design geometrical features to develop an analytical cost estimation method for axisymmetric components in open-die forging. In: 29th CIRP Design 2019 (CIRP Design 2019)

32. Masel DT, Young IIWA, Judd RP (2010) A rule-based approach to predict forging volume for cost estimation during product design. Int J Adv Manuf Technol 46:31-41

33. Numthong C, Butdee S (2014) The knowledge based system for forging process design based on case-based reasoning and finite element method. KMUTNB International Journal of Applied Science Technology 5(2):45-54

34. Ozcan B, Figlalı A (2014) Artificial neural networks for the cost estimation of stamping dies. Neural Computation \& Application

35. Aram S, Eastman C, Beetz J (2014) Qualitative and quantitative cost estimation: a methodology analysis. Proceedings of International Conference on Computing in Civil and Building Engineering, 2014

36. Jha SK (2016) Cost optimization of a forged steel crankshaft in global manufacturing environment. Int J Mech Eng Res Technol 2(2):16-28

37. Lin C-K, Shaw HJ (2017) Feature-based estimation of preliminary costs in shipbuilding. Ocean Eng 144:305-319

38. Jung JY, Ahluwalia RS (1991) FORCOD: A coding and classification system for formed parts. J Manuf Syst 10(3):223-232

39. Ali S, Durupt A, Adragna PA (2013) reverse engineering for manufacturing approach: based on the combination of $3 \mathrm{D}$ and knowledge information. Smart Product Engineering:137-146

40. Bhatt MR, Buch S (2016) Application of rule based and expert systems in various manufacturing processes - a review. In: Proceedings of first international conference on information and communication technology for intelligent systems, vol 1, pp 459465

41. Rehman S, Guenov MD (1998) A methodology for modelling manufacturing costs at conceptual design. Comput Ind Eng 35: 623-626

42. Zhang Y, Luo X, Zhang H, Sutherland JW (2014) A knowledge representation for unit manufacturing processes. Int J Adv Manuf Technol 73(5-8):1011-1031

43. Bayramoglu M, Polat H, Geren N (2008) Cost and performance evaluation of different surface treated dies for hot forging process. J Mater Process Technol 205(1-3):394-403

44. Berlioz M, Marin P, Tichkiewitch S (1999) A fast and reliable cost-estimation tool for hot-forged parts. Integrated Design and Manufacturing in Mechanical Engineering (IDMME) 98:595-602

45. Choi SH, Dean TA (1984) Computer aids to data preparation for cost estimation. Int J Mach Tool Des Res 24(2):105-119

46. Esawi AMK, Ashby MF (1998) Cost-based ranking for manufacturing process selection. Integrated Design and Manufacturing in Mechanical Engineering (IDMME) 98:603610

47. Esawi AMK, Ashby MF (2003) Cost estimates to guide preselection of processes. Mater Des 24(8):605-616

48. Esche SK, Chassapis C, Manoochehri S (2001) 2001 Concurrent product and process design in hot forging. Institute of Concurrent Engineering 9(1):48-54 
49. Feng SC, Song EY (2003) A manufacturing process information model for design and process planning integration. J Manuf Syst 22(1):1-15

50. Forcellese A, Gabrielli F, Ruffini R (1996) Application of a decision making method in the forging condition optimisation for manufacturing automotive components. J Mater Process Technol 60(1-4):125-132

51. Harzendorf F, Azzam B, Schelenz R, Jacobs G (2018) Manufacturing cost - a critical evaluation criteria for new developments in wind turbine drivetrain technologies. J Phys Conf Ser 1102:012024

52. Jönsson M, Andersson C, Ståhl JE (2008) A general economic model for manufacturing cost simulation. Manufacturing Systems and Technologies for the New Frontier:33-38

53. Knight WA, Poli CR, Boothroyd G (1982) Design for economical use of forging: indication of general relative forging costs. CIRP Ann 31(1):159-163

54. Knight WA (1992) Simplified early cost estimating for hot-forged parts. Int J Adv Manuf Technol 7:159-167

55. Kulon J, Broomhead P, Mynors DJ (2006) 2006 Applying knowledge-based engineering to traditional manufacturing design. Int $\mathrm{J}$ Adv Manuf Technol 30:945-951

56. Lange K (1985) Cost minimization in small quantity production of stepped shafts by combined NC-radial forging and NC-turning. A new approach to flexible manufacturing systems. Annals of the CIRP:34/2

57. Laureijs RE, Roca JB, Narra SP, Montgomery C, Beuth JL, ERH F (2017) Metal additive manufacturing: cost competitive beyond low volumes. J Manuf Sci Eng 139(8):081010-1-081010-9

58. Majerus JN, Mimnagh ML, Jannone JA, Tenney DA, Lampheard SP (1998) Blending hierarchical economic decision matrices (EDM) with FE and stochastic modeling. Detailing EDM Finite Elements in Analysis and Design II 30(3):219-234

59. Martin P, Dantan JY, Siadat A (2007) Cost estimation and conceptual process planning. Digital Enterprise Technology

60. Massoni BR, Campbell MI (2017) Automated design of closeddie forgings. In: Proceedings of the ASME 2017 International Design Engineering Technical Conferences

61. Nagahanumaiah NP, Ravi B, Mukherjee NP (2005) An integrated framework for die and mold cost estimation using design features and tooling parameters. Int J Adv Manuf Technol 26:1138-1149

62. Nakagawa T, Tanaka T, Amano T (1978) Powder forging of high strength brass and its application to automobile parts. J Mech Work Technol 2(2):179-195

63. Rezaie K, Ostadi B (2006) The activity-based costing approach for estimation of part's cost in FMS with F (2)-degree automation: a case study in a forging industry. Inf Technol $\mathrm{J}$

64. Rezaie K, Ostadi B, Torabi SA (2008) Activity-based costing in flexible manufacturing systems with a case study in a forging industry. Int J Prod Res 46:1047-1069

65. Sonmez FO, Ozturk M, Kocaoglan S (2016) Concurrent design and process optimization of forging. Comput Struct 167:24-36

66. Yu JC, Lotfi S, Ishii K, Trageser A (1993) Process selection for the design of aluminum components. Adv Eng Softw 18(3):177-186

67. Aston JL, Martinelli G (1978) Considerations on forging with hammers or mechanical presses for short and medium runs. $\mathrm{J}$ Mech Work Technol 2:291-305

68. Bariani PF, Berti G, D'Angelo L (1993) Tool cost estimating at the early stages of cold forging process design. CIRP Ann 42(1): 279-282

69. Creese RC, Patrawala TB (1998) The return of feature based cost modeling. Proceedings of SPIE - The International Society for Optical Engineering, 3517

70. Denkena B, Rudzio H, Brandes A (2006) Methodology for dimensioning technological interfaces of manufacturing process chains. CIRP Ann 55(1):497-500
71. Loyer JL, Henriques E, Fontul M, Wiseall S (2016) Comparison of Machine Learning methods applied to the estimation of manufacturing cost of jet engine components. Int J Prod Econ 178:109-119

72. Martinelli I, Campi F, Checcacci E, Lo Presti GM, Pescatori F, Pumo A, Germani M (2019) cost estimation method for gas turbine in conceptual design phase. 29th CIRP Design 2019 (CIRP Design 2019)

73. Blanch R, Ferrer I, Garcia-Romeu ML (2012) A model to build manufacturing process chains during embodiment design phases. Int J Adv Manuf Technol 59:421-432

74. Venkatachalam AR, Mellichamp JM, Miller DM (1993) A knowledge-based approach to design for manufacturability. J Intell Manuf 4(5):355-366

75. Mandolini M, Campi F, Favi C, Germani M, Raffaeli R (2020) A framework for analytical cost estimation of mechanical components based on manufacturing knowledge representation. Int $\mathrm{J}$ Adv Manuf Technol 107:1131-1151

76. ASM (2005) Handbook Volume 14A: Metalworking: Bulk Forming. ASM International 2005

77. Markov OE, Perig AV, Zlygoriev VN, Markova MA, Grin AG (2017) A new process for forging shafts with convex dies. Research into the stressed state. Int J Adv Manuf Technol 90: $801-818$

78. Gronostajski Z, Pater Z, Madej L, Gontarz A, Lisiecki L, Lukaszek-Solek A, Luksza J, Mróz S, Muskalski Z, Muzykiewicz W, Pietrzyk M, Sliwa RE, Tomczak J, Wiewiórowska S, Winiarski G, Zasadzinski J, Ziólkiewicz S (2019) Recent development trends in metal forming. Arch Civ Mech Eng 19:898-941

79. Kalpakjian S, Schmid S (2017) Manufacturing Processes for Engineering Materials, 6th edn Pearson

80. Metal Forming Handbook / Schuler (c) Springer-Verlag Berlin Heidelberg 1998

81. Sheljaskow S, Dübler A (1991) Entwicklungsstand und Einsatzbereich der Halbwarmumformung, Verein deutscher Werkzeugmaschinenfabriken e. V. (VDW) Study.

82. Lange K, Keller HJ (1994) Some aspects of the economic production of complex components by cold forging and machining. J Mater Process Technol 46

83. Alexander JM (1983) The economics of alternative methods of metal processing. CIRP Ann 32(2):551-558

84. Min DK, Kim ME (2003) A study on precision cold forging process improvements for the steering yoke of automobiles by the rigid-plastic finite-element method. J Mater Process Technol 138(1-3):339-342

85. Doege E, NägeleH (1994) FE simulation of the precision forging process of bevel gears. CIRP Ann 43(1):241-244

86. Wright PW (1987) Near-net shaping - The key to new materials exploitation. Mater Des 8(3):142-146

87. Nägele H, Wörner H, Hirschvogel M (2000) Automotive parts produced by optimizing the process flow forming - machining. J Mater Process Technol 98(2):171-175

88. Movahhedy MR, GhaeiaA TAK (2005) Study of the effects of die geometry on deformation in the radial forging process. J Mater Process Technol 170(1-2):156-163

89. Park HS, Ayu FR, Kumar S (2018) Preform optimization for bevel gear of warm forging process. 51st CIRP Conference on Manufacturing Systems

90. Ferrer L, Rios J, Ciuran J, Garcia-Romeu ML (2010) Methodology for capturing and formalising DFM Knowledge. Robot Comput Integr Manuf 26(5):420-429

91. Altan T, Vazquez V (2000) Die design for flashless forging of complex parts. J Mater Process Technol 98(1):81-89 
92. Abumeri GH, Chamis CC (1997) T/BEST: a computer code for assessing the benefits of advanced aerospace. Adv Eng Softw 28: 231-238

93. Altan T, Miller RA (1990) Design for forming and other near net shape manufacturing processes. CIRP Annals 39(2):609-620

94. Bonilla Hernández AE, Beno T, Fredriksson C (2017) Energy and cost estimation of a feature-based machining operation on HRSA. Procedia CIRP 61:511-516

95. Boujut JF, Léon JC, Gauvrit L (1996) A systematic approach to the surface modelling of forged parts. Integrated Design and Manufacturing in Mechanical Engineering:277-285

96. Chander S, Chawla V (2017) Failure of hot forging dies -an updated perspective. In: 5 th International Conference of Materials Processing and Characterization (ICMPC 2016)

97. Fereshteh SF, Jaghargh PV (2008) An experimental comparative study of blocker die design for axisymmetric forging components. In: The 12th International Conference Metal forming 2008, Krakow, Poland

98. Fereshteh-Saniee F, Hosseini AH (2006) The effects of flash allowance and bar size on forming load and metal flow in closed die forging. J Mater Process Technol 177:261-265

99. Fereshteh-Saniee F, Daneshzad-Moghaddam B (2004) A new CAD system for finisher die design of an axisymmetric forging component with arbitrary profile. J Mater Process Technol 153154:157-163

100. Fujikawa S, Kitamura Y, Shimamura S (1991) Application of numerical methods for the aluminum casting/forging process. $\mathrm{J}$ Mater Process Technol 27(1-3):93-110

101. Haque I, Jackson JE, Gangjee T, Raikar A (1987) Empirical and finite element approaches to forging die design: A state-of-the-art survey. J Mater Shap Technol 5(1):23-33

102. Hartley P, Sturgess CEN, Dean TA, Rowe GW (1987) Forging die design and flow simulation: Their integration in intelligent knowledge-based systems. J Mech Work Technol 15(1):1-13

103. Jeitler B, Atzwanger M (2011) Minimization of risks and difficulties from design to mass production for powertrain components and modules. SAE 2011 World Congress \& Exhibition (SAE Technical Paper 2011-01-0524)

104. Keife H, Ståhlberg U (1984) The influence of flash design on material flow and tool pressure in closed-die forging: a practical example. J Mech Work Technol 9(1):37-52

105. Marini D, Corney JR (2017) A methodology for near net shape process feasibility assessment. Production \& Manufacturing Research

106. Thibault A, Siadat A, Bigot R, Martin P (2007) Proposal for product process integration using classification and rules. In: EUROCON 2007 The International Conference on "Computer as a Tool" Warsaw, September 9-12

107. Thibault A, Siadat A, Sadeghi M, Bigot R, Martin P (2009) Knowledge formalization for product-process integration applied to forging domain. Int J Adv Manuf Technol 44(11-12):11161132

108. Tichkiewitch S, Véron M (1998) Integration of Manufacturing Processes in Design. CIRP Ann 47(1):99-102

109. Yoon HS, Lee JY, Kim HS, Kim MS, Kim ES, Shin YJ, Chu WS, Ahn SH (2014) A comparison of energy consumption in bulk forming, subtractive, and additive processes: Review and case study. Int J Precis Eng Manuf-Green Technol 1(3):261-279
110. Zaman UK, Siadat A, Rivette M, Baqai AA, Qiao L (2017) Integrated product-process design to suggest appropriate manufacturing technology: a review. Int J Adv Manuf Technol 91(1-4):1409-1430

111. Aziz S, Chassapis C (2005) A decision-making framework model for design and manufacturing of mechanical transmission system development. Eng Comput 21:164-176

112. Balendra R, Lu X (2001) Finite element simulation for die-cavity compensation. J Mater Process Technol 115(2, 4):227-232

113. Ma Y, Qin Y, Balendra R (2005) Forming of hollow gear-shafts with pressure-assisted injection forging (PAIF). J Mater Process Technol 167(2-3):294-301

114. Ou H, Balendra R (1998) Preform design for forging of aerofoil sections using FE simulation. J Mater Process Technol 80-81: 144-148

115. Ou H, Armstrong CG, Price MA (2003) Die shape optimisation in forging of aerofoil sections. J Mater Process Technol 132(1-3): $21-27$

116. Abdullah AB, Samad Z (2007) Cold forging die design: recent advanced and future trends. J Appl Sci 7(6):868-876

117. Kong LX, Nahavandi S (2002) On-line tool condition monitoring and control system in forging processes. J Mater Process Technol 125-126:464-470

118. Lee R. S., Chang C.W., Chang T.W. 2017 Development of knowledge-expandable ontology-based expert system for process planning in cold forging of flange nuts. International Conference on the Technology of Plasticity, ICTP 2017, Cambridge, United Kingdom

119. Roy S, Ghosh S, Shivpuri R (1997) A new approach to optimal design of multi-stage metal forming processes with micro genetic algorithms. Int J Mach Tools Manuf 37(1):29-44

120. Grandhi RV, Belur BK (2004) Geometric deviations in forging and cooling operations due to process uncertainties. J Mater Process Technol 152(2):204-214

121. Lee JS, Hong SS, Lee SH, Cho NC, Kim NH (1994) Application of physical modeling, FEM and knowledge-based process planning program to forging process design. J Mater Process Technol 45(1-4):709-714

122. Campi F, Mandolini M, Favi C, Checcacci E, Germani M (2020) An analytical cost estimation model for the design of axisymmetric components with open-die forging technology. Int J Adv Manuf Technol 110:1869-1892

123. Zhao G, Wright E, Grandhi RV (1997) Sensitivity analysis based preform die shape design for net-shape forging. Int J Mach Tools Manuf 37(9):1251-1271

124. Ben-Arieh D (2000) Cost estimation system for machined parts. Int J Prod Res 38(17)

125. Favi C, Germani M, Mandolini M (2017) Analytical cost estimation model in high pressure die casting. Procedia Manufacturing 11:526-535

126. Jung J-Y (2002) Manufacturing cost estimation for machined parts based on manufacturing features. J Intell Manuf 13(4):227-238

127. Madan J, Rao PVM, Kundra TK (2007) System for early cost estimation of die-cast parts. Int J Prod Res 45(20):2007

Publisher's note Springer Nature remains neutral with regard to jurisdictional claims in published maps and institutional affiliations. 